\title{
Dysregulation of the (immuno)proteasome pathway in malformations of cortical development
}

J. van Scheppingen ${ }^{1 \dagger}$, D. W. M. Broekaart ${ }^{1 \dagger}$, T. Scholl², M. R. J. Zuidberg ${ }^{1}$, J. J. Anink1, W. G. Spliet ${ }^{5}$, P. C. van Rijen ${ }^{6}$, T. Czech ${ }^{3}$, J. A. Hainfellner ${ }^{4}$, M. Feucht ${ }^{2}$, A. Mühlebner ${ }^{1}$, E. A. van Vliet ${ }^{1+}$ and E. Aronica ${ }^{1,7,8^{*}+}$

\begin{abstract}
Background: The proteasome is a multisubunit enzyme complex involved in protein degradation, which is essential for many cellular processes. During inflammation, the constitutive subunits are replaced by their inducible counterparts, resulting in the formation of the immunoproteasome.
\end{abstract}

Methods: We investigated the expression pattern of constitutive ( $\beta 1, \beta 5)$ and immunoproteasome ( $\beta 1 \mathrm{i}, \beta 5 \mathrm{i})$ subunits using immunohistochemistry in malformations of cortical development (MCD; focal cortical dysplasia (FCD) Ila and b, cortical tubers from patients with tuberous sclerosis complex (TSC), and mild MCD (mMCD)). Glial cells in culture were used to elucidate the mechanisms regulating immunoproteasome subunit expression.

Results: Increased expression was observed in both FCD II and TSC; $\beta 1, \beta 1 i, \beta 5$, and $\beta 5 i$ were detected (within cytosol and nucleus) in dysmorphic neurons, balloon/giant cells, and reactive astrocytes. Glial and neuronal nuclear expression positively correlated with seizure frequency. Positive correlation was also observed between the glial expression of constitutive and immunoproteasome subunits and IL-1 $\beta$. Accordingly, the proteasome subunit expression was modulated by IL-1 $\beta$ in human astrocytes in vitro. Expression of both constitutive and immunoproteasome subunits in FCD II-derived astroglial cultures was negatively regulated by treatment with the immunomodulatory drug rapamycin (inhibitor of the mammalian target of rapamycin (mTOR) pathway, which is activated in both TSC and FCD II).

Conclusions: These observations support the dysregulation of the proteasome system in both FCD and TSC and provide new insights on the mechanism of regulation the (immuno)proteasome in astrocytes and the molecular links between inflammation, mTOR activation, and epilepsy.

Keywords: Immunoproteasome, Inflammation, Immunohistochemistry, Tuberous sclerosis complex, Focal cortical dysplasia, Epilepsy, Astrocytes, Inflammation

Abbreviations: FCD, Focal cortical dysplasia; IRS, Immunoreactivity score; MCD, Malformations of cortical development; MTLE, Mesial temporal lobe epilepsy; PBS, Phosphate-buffered saline; TSC, Tuberous sclerosis complex

\footnotetext{
* Correspondence: e.aronica@amc.uva.nl

${ }^{\dagger}$ Equal contributors

${ }^{1}$ Academic Medical Center, Department of (Neuro)Pathology, University of

Amsterdam, Meibergdreef 9, 1105 AZ Amsterdam, The Netherlands

${ }^{7}$ Swammerdam Institute for Life Sciences, Center for Neuroscience, University

of Amsterdam, Amsterdam, The Netherlands

Full list of author information is available at the end of the article
} 


\section{Background}

The proteasome is an evolutionarily conserved multicatalytic proteinase complex representing a major protein degradation system, present in the nucleus and cytoplasm of eukaryotic cells, that regulates diverse biological processes essential for cell survival [1-4]. The proteolytic complex of the proteasome is represented by a catalytic $20 S$ core particle, a barrel-shaped complex consisting of four heptameric rings, composed of non-identical $\alpha$ or $\beta$ subunits $[2,5,6]$. The catalytic activity is restricted to three of the beta subunits $\beta 1, \beta 2$, and $\beta 5$, which have specific cleavage preferences, and are constitutively expressed in most tissues. Under certain conditions associated with the release of immune-modulatory cytokines (i.e., interferon- $\gamma$, IFN- $\gamma$ ), a specialized type of proteasome called the immunoproteasome can be generated by the incorporation of the inducible subunits, $\beta 1$ i (PSMB9; LMP2, low molecular weight protein 2), 32 i (PSMB10; LMP10, MECL-1, multicatalytic endopeptidase complex-like 1), and $\beta 5$ i (PSMB8; LMP7, low molecular weight protein 7) [7, 8]. Increasing evidence supports a key role of the immunoproteasome in the regulation of immune cell function, including both the adaptive and the innate immune response [9-11]. A deregulation of the immunoproteasome system, with induction of $\beta 1 \mathrm{i}$ and $\beta 5 \mathrm{i}$ subunits in the neurons and/or glial cells, has been reported in neurodegenerative diseases ([12-14] for review, see $[15,16])$. In particular, recent studies have pointed to the role of immunoproteasome in glial cells, suggesting a novel interaction between immunoproteasome and glia-mediated inflammatory response, resulting in a pro-inflammatory environment $[14,16]$. Interestingly, induction of $\beta 1 \mathrm{i}$ and $\beta 5 \mathrm{i}$ subunits has been also observed in specimens of patients with pharmacoresistent mesial temporal lobe epilepsy (MTLE; [17]). Moreover, recent experimental data support a role for the $\beta 5 \mathrm{i}$ subunit in modulating seizure generation in epileptic tissue, and interestingly, this subunit was not upregulated in rats exposed to pilocarpine but not developing SE and spontaneous seizures [18].

In the present study, we investigated the expression and cellular distribution of both constitutive $(\beta 1, \beta 5)$ and immunoproteasome $(\beta 1 i, \beta 5 i)$ subunits using immunohistochemistry in a large cohort of patients with malformations of cortical development (MCD; including focal cortical dysplasia (FCD) type II and tuberous sclerosis complex (TSC) cortical tubers), evaluating a possible relationship between changes in the expression of these subunits and the clinical course of epilepsy. To provide better insights into the mechanisms underlying the astroglial regulation of immunoproteasome subunits, we studied their expression in response to IL-1 $\beta$ stimulation in both human fetal astrocytes and FCD-derived cells. Since both FCD II and TSC are associated with constitutive activation of the mammalian target of rapamycin (mTOR) pathway $[19,20]$, we further evaluated the effect of rapamycin (inhibitor of the mTOR pathway) in FCD II-derived cell cultures.

\section{Methods \\ Subjects}

The cases included in this study were obtained from the archives of the Departments of Neuropathology of the Academic Medical Center (AMC, University of Amsterdam, The Netherlands), the University Medical Center Utrecht (UMCU, The Netherlands), and the Medical University Vienna (MUV, Austria). A total of 23 brain tissue specimens, removed from patients undergoing surgery for intractable epilepsy, were examined. The tissue was obtained and used in accordance with the Declaration of Helsinki and the AMC Research Code provided by the Medical Ethics Committee and approved by the committee of the UMCU Biobank. This study was also approved by the Ethical Committee of the Medical University of Vienna. All cases were reviewed independently by two neuropathologists, and the diagnosis of FCD was confirmed according to the international consensus classification system recently proposed for grading FCD [21]. All patients with cortical tubers fulfilled the diagnostic criteria for TSC [22]. None of the FCD patients fulfilled the diagnostic criteria for TSC. Table 1 summarizes the clinical findings of patients with MCD and epilepsy (6 mild MCD (mMCD), 5 FCD IIa, 6 FCD IIb, 6 TSC tubers: 4 TSC2/2 TSC1; pre-operative seizure frequency/month, mean \pm SEM: mMCD $19.8 \pm 6.7$; FCD II $149 \pm 68.7$; TSC $114.8 \pm 24.2$ ); seizure frequencies were recorded (video-electroencephalographic monitoring) at the time of the preoperative

Table 1 Summary of clinical findings of epilepsy patients and controls

\begin{tabular}{|c|c|c|c|c|c|}
\hline Pathology type & Number of cases & Gender (M/F) & Mean age (years/range) & Localization & Mean duration of epilepsy (years/range) \\
\hline mMCD & 6 & $5 / 1$ & $21.5(19-27)$ & $3 \mathrm{fr} / 3 \mathrm{t}$ & $17.3(11-32)$ \\
\hline FCD \|la & 5 & $3 / 2$ & $34.2(18-45)$ & $4 \mathrm{fr} / 1 \mathrm{t}$ & $22.4(14-26)$ \\
\hline FCD Ilb & 6 & $2 / 4$ & $33(21-45)$ & $4 \mathrm{fr} / 2 \mathrm{t}$ & $24(15-40)$ \\
\hline Cortical tubers (TSC) & 6 & $3 / 3$ & $7.1(3-16)$ & $4 \mathrm{fr} / 2 \mathrm{t}$ & $5.8(0.8-13)$ \\
\hline Controls/autopsy & 14 & $8 / 6$ & $27.0(2-48)$ & $6 \mathrm{fr} / 8 \mathrm{t}$ & - \\
\hline
\end{tabular}

FCD focal cortical dysplasia, TSC tuberous sclerosis complex, $m M C D$ mild malformations of cortical development, $M$ male, $F$ female, fr frontal, $t$ temporal 
evaluation. One tuber specimen was obtained postmortem (age 32 years; male; TSC2). Hippocampal specimens from patients with Alzheimer's disease (AD; $n=4$; 3 females and 1 male; Braak stages V and VI, age $81.7 \pm 2.8$ ) were also examined as positive controls. In addition, normal-appearing control cortex and white matter were obtained at autopsy from six young adult control patients (Table 1), without history of seizures or other neurological diseases. All autopsies were performed within $24 \mathrm{~h}$ after death.

\section{Tissue preparation and immunohistochemistry}

Brain tissue from control and MCD patients was fixed in $10 \%$ buffered formalin and embedded in paraffin. Paraffin-embedded tissue was sectioned at $5 \mu \mathrm{m}$, mounted on pre-coated glass slides (Star Frost, Waldemar Knittel $\mathrm{GmbH}$, Braunschweig, Germany), and used for histology and immunohistochemistry. One representative paraffin block per case was sectioned, stained, and assessed. Sections were processed for hematoxylin eosin stainings, as well as for immunohistochemical stainings for a number of neuronal and glial markers and antibodies against the constitutive $(\beta 1, \beta 5)$ and immunoproteasome $(\beta 1 \mathrm{i}, \beta 5 \mathrm{i})$ subunits (Table 2). These antibodies have been extensively tested on human liver and brain tissues [23, 24], including surgical brain specimens from patients with mesial temporal lobe epilepsy revealing bands at the expected molecular weight ([17]; Additional file 1: Figure S1). To detect differences in labeling related to technical variables such as tissue fixation, we also tested the antibodies in specimens of selected regions (temporal cortex/hippocampus) collected at autopsy and immediately fixed in formalin for $24 \mathrm{~h}$ (same fixation time used for the surgical specimens); no differences in the immunoreactivity pattern were observed.

Single-label immunohistochemistry was performed as previously described [25]. Sections were deparaffinated in xylene, rinsed in ethanol (100, 95, and $70 \%)$ and incubated for $20 \mathrm{~min}$ in $0.3 \%$ hydrogen peroxide diluted in methanol. Antigen retrieval was performed using a pressure cooker in $0.1 \mathrm{M}$ citrate buffer $\mathrm{pH} 6.0$ at $120^{\circ} \mathrm{C}$ for $10 \mathrm{~min}$. Slides were washed with phosphate-buffered saline (PBS; 0.1 M, pH 7.4) and incubated overnight with the primary antibody in PBS at $4{ }^{\circ} \mathrm{C}$. After washing in PBS, sections were stained with a polymer-based peroxidase immunohistochemistry detection kit (PowerVision Peroxidase System, ImmunoVision, Brisbane, CA, USA). The 3,3'-diaminobenzidine tetrahydrochloride was used as chromogen. Sections were dehydrated in alcohol and xylene and coverslipped.

Double-labeling of $\beta 1, \beta 1 \mathrm{i}, \beta 5$, or $\beta 5 \mathrm{i}$ with NeuN (neuronal nuclear protein (NeuN; mouse clone MAB377; Chemicon, Temecula, CA, USA; 1:2000), GFAP (polyclonal rabbit, DAKO, Glostrup, Denmark; 1:4000, or monoclonal mouse, Sigma-Aldrich, St. Louis, MO, USA; 1:4000), HLA-I (mouse clone HC-10, 1:200), or HLA-II (mouse anti-human leukocyte antigen (HLA)-DP, DQ, DR, mouse clone CR3/43; DAKO; 1:400) was performed as previously described [26]). Sections were incubated with BrightVision poly-alkaline phosphatase (AP)-antirabbit or anti-mouse (Immunologic, Duiven, The Netherlands) for $30 \mathrm{~min}$ at room temperature and washed with PBS. AP activity was visualized with the AP substrate kit III Vector Blue (SK-5300, Vector Laboratories Inc., CA, USA). To remove the first primary antibody, sections were incubated at $121{ }^{\circ} \mathrm{C}$ in citrate buffer (10 $\mathrm{mM} \mathrm{NaCi}, \mathrm{pH}$ 6.0) for $10 \mathrm{~min}$. Incubation with the second primary antibody was performed overnight at $4{ }^{\circ} \mathrm{C}$. Sections with primary antibody other than rabbit were incubated with post-antibody blocking from the BrightVision+ system (containing rabbit- $\alpha$-mouse IgG; Immunologic, Duiven, The Netherlands). AP activity was visualized with the alkaline phosphatase substrate kit I Vector Red (SK-5100; Vector Laboratories Inc., CA,

Table 2 Immunohistochemistry: primary antibodies

\begin{tabular}{|c|c|c|c|}
\hline Antigen & Primary antibody & Source & Dilution \\
\hline Glial fibrillary acidic protein (GFAP) & Rabbit polyclonal & DAKO, Glostrup, Denmark & $1: 4000$ \\
\hline Neuronal nuclear protein (NeuN) & Mouse clone MAB377 & Chemicon, Temecula, CA, USA & $1: 2000$ \\
\hline Phospho-S6 ribosomal protein (pS6) & Ser235/236; rabbit polyclonal & Cell Signaling Technology, Beverly, MA, USA & $1: 50$ \\
\hline Interleukin $1 \beta$ & Goat polyclonal & Santa Cruz Bio., Delaware CA, USA & $1: 70$ \\
\hline MHC class I (HLA A, B, and C; HLA-I) & Mouse clone $\mathrm{HC}-10$ & a & $1: 200$ \\
\hline MHC class II (HLA-DP, DQ, DR; HLA-II) & Mouse clone CR3/43 & DAKO, Glostrup, Denmark & $1: 400$ \\
\hline Proteasome $\beta 1$ & Mouse monoclonal lgG1 & Enzo Life Sciences/Biomol, Farmingdale, NY, USA & $1: 200$ \\
\hline Proteasome $\beta 5$ & Rabbit polyclonal & Enzo Life Sciences/Biomol & 1:500 \\
\hline Proteasome $\beta 1 \mathrm{i}$ & Mouse monoclonal lgG1 & Enzo Life Sciences/Biomol & $1: 200$ \\
\hline Proteasome $\beta 5 i$ & Mouse monoclonal lgG1 & Enzo Life Sciences/Biomol & $1: 200$ \\
\hline
\end{tabular}

MHC major histocompatibility complex

${ }^{a}$ Gift from Prof. J. Neefjes, Netherlands Cancer Institute, The Netherlands 
USA). Sections incubated without the primary antibody, with preimmune sera, or with the antibody preincubated with the antigenic peptide (for the polyclonal $\beta 5$ ) were essentially blank.

\section{Evaluation of histology and immunohistochemistry}

All labeled tissue sections were evaluated by two independent observers for the presence or absence of various histopathological parameters and specific immunoreactivity (IR) for the different markers used for the diagnosis of mMCD, FCD subtypes, and TSC tubers. We also semi-quantitatively evaluated the IR (nucleus and cytoplasm in glial and neuronal cells) of $\beta 1, \beta 1 i, \beta 5$, and $\beta 5 i$. The intensity of the staining was evaluated using a scale of 0-3 (0: no; 1 : weak; 2: moderate; 3 : strong staining). All areas of the lesion were examined, and the score represents the predominant cell staining intensity found in each case. The frequency of $\beta 1, \beta 1 i, \beta 5$, or $\beta 5 i$ positive cells ((1) rare; (2) sparse; (3) high) was also evaluated to give information about the relative number of positive cells within the lesion. We also evaluated intensity and frequency of pS6 and IL-1 $\beta$ staining. As described in previous studies [25, 27], the product of the intensity and frequency scores was taken to give the overall score (total score; immunoreactivity score (IRS), Table 3). Quantification of signal intensity using ImageJ software was performed for $\beta 1 \mathrm{i}$ and $\beta 5 \mathrm{i}$ subunits (Additional file 2: Figure $\mathrm{S} 2$ ).

\section{Cell cultures}

Primary fetal astrocyte-enriched cell cultures were obtained from human fetal brain tissue (14-19 weeks of gestation) obtained from the HIS-Mouse (human immune system mouse) facility of the AMC, Amsterdam. All materials have been collected from donors from whom a written informed consent for the use of the material for research purposes had been obtained by the Bloemenhove Clinic (Heemstede, The Netherlands); these informed consents are kept together with the medical record of the donor by the clinic. The tissue was obtained in accordance with the Declaration of Helsinki and the AMC Research Code provided by the Medical Ethics Committee of the AMC. Cell isolation was performed as described elsewhere [28-30]. Briefly, after the removal of the blood vessels, the tissue was mechanically minced into smaller fragments and enzymatically digested by incubating at $37{ }^{\circ} \mathrm{C}$ for $30 \mathrm{~min}$ with $2.5 \%$ trypsin (Sigma-Aldrich; St. Louis, MO,

Table 3 Immunoreactivity of $\beta 1, \beta 1 i, \beta 5$, and $\beta 5$ i proteasome subunits in the cortex

\begin{tabular}{|c|c|c|c|c|c|c|c|}
\hline & & \multicolumn{2}{|c|}{ (Dysmorphic) neurons } & \multicolumn{2}{|l|}{ Glia } & \multicolumn{2}{|c|}{ Balloon/giant cells } \\
\hline & & Cytoplasm & Nucleus & Cytoplasm & Nucleus & Cytoplasm & Nucleus \\
\hline \multirow[t]{5}{*}{$\beta 1$} & Control & $2(2-3)$ & 0 & $0(0-1)$ & 0 & - & - \\
\hline & $\mathrm{mMCD}$ & $2 \cdot \sim$ & $1(1-2)^{* 0} \sim$ & $0 \cdot{ }^{\circ} \sim$ & $0^{\circ} \sim$ & - & - \\
\hline & FCDIla & $5(4-9)^{*}$ & $1(1-2)^{* \circ}$ & $2.5(2-4)^{*}$ & $2.5(2-4)^{* 0}$ & - & - \\
\hline & FCDIlb & $7.5(3-9)^{*}$ & $6(3-6)^{*}$ & $4(3-6)^{*}$ & $5(4-6)^{*}$ & $3.5(3-6)$ & $6(4-9)$ \\
\hline & TSC & $6.5(4-9)^{*}$ & $5(4-9)^{*}$ & $7.5(4-9)^{*}$ & $7.5(4-9)^{*}$ & $6(3-9)$ & $9(6-9)$ \\
\hline \multirow[t]{5}{*}{$\beta 1 i$} & Control & $0(0-1)$ & $0(0-1)$ & $1(0-1)$ & $0(0-2)$ & - & - \\
\hline & $\mathrm{mMCD}$ & $00^{\circ} \sim$ & $0 *^{\circ} \sim$ & $0(0-1))^{\circ} \sim$ & $00^{\circ} \sim$ & - & - \\
\hline & FCDIla & $3(2-4)^{*}$ & $4(3-6)^{*} \sim$ & $3.5(3-4)^{*}$ & $3(3-6)^{*} \sim$ & - & - \\
\hline & FCDIlb & $4(2-4)^{*}$ & $6(3-9)^{*}$ & $6(3-9)^{*}$ & $5(3-6)^{*}$ & $4(3-4)$ & $7.5(3-9)$ \\
\hline & TSC & $3.5(2-6)^{*}$ & $6(4-9)^{*}$ & $5(3-9)^{*}$ & $5(2-9)^{*}$ & $4(3-6)$ & $7.5(4-9)$ \\
\hline \multirow[t]{5}{*}{$\beta 5$} & Control & $1(0-1)$ & $1(0-1)$ & 0 & $0(0-1)$ & - & - \\
\hline & $\mathrm{mMCD}$ & $0^{\circ} \sim$ & $6^{*}=$ & $0^{\circ} \sim$ & $0={ }^{\circ} \sim$ & - & - \\
\hline & FCDIla & $3.5(2-4)^{*} \sim$ & $7.5(6-9)^{*}$ & $1.5(0-2)^{*} \sim$ & $2.5(1-4)^{*} \sim$ & - & - \\
\hline & FCDIlb & $6(4-6)^{* 0}$ & $9(6-9)^{*}$ & $3.5(3-4)^{*}$ & $6(4-9)^{* \circ}$ & $4(3-6)$ & $9(6-9)$ \\
\hline & TSC & $3.5(3-4)^{*}$ & $7.5(6-9)^{*}$ & $2.5(2-4)^{*}$ & $2.5(2-4)^{*}$ & $6(4-9)$ & $9(6-9)$ \\
\hline \multirow[t]{5}{*}{$\beta 5 i$} & Control & 0 & 0 & $0(0-1)$ & $1(1-2)$ & - & - \\
\hline & $\mathrm{mMCD}$ & $0^{\circ}$ & $0: \sim$ & $0(0-1)^{\circ} \sim$ & $0^{\circ} \sim$ & - & - \\
\hline & FCDIla & $0^{\circ}$ & $1.5(1-4)^{*}$ & $0(0-2)^{\circ}$ & $0(0-2) \sim$ & - & - \\
\hline & FCDIlb & $0(0-1)^{\circ}$ & $4(3-6)^{\circ}$ & $2.5(1-3)^{\circ}$ & $3(1-6)$ & $0(0-1)^{\circ}$ & $6(4-6)^{\circ}$ \\
\hline & TSC & $6(4-9)^{*}$ & $0.5(0-1)$ & $6(4-9)^{*}$ & $1.5(1-2)^{*}$ & $9(6-9)$ & $0.5(0-1)$ \\
\hline
\end{tabular}

Immunoreactivity score (IRS) is given as median (minimum-maximum). IRS is defined as intensity score multiplied by frequency score (see "Methods" section). Kruskall-Wallis test followed by Mann-Whitney $U$ test

*Different compared to controls; ${ }^{\circ}$ different compared to TSC; -different compared to FCDIla; $\sim$ different compared to FCDIlb, $p<0.05$ 
USA). The tissue was washed with incubation medium containing Dulbecco's modified Eagle's medium (DMEM)/HAM F10 (1:1) medium (Gibco, Life Technologies, Grand Island, New York, USA), supplemented with 50 units $/ \mathrm{ml}$ penicillin, $50 \mu \mathrm{g} / \mathrm{ml}$ streptomycin, and $10 \%$ fetal calf serum (FCS; Gibco, Life Technologies, Grand Island, New York, USA) and triturated by passing through a $70 \mu \mathrm{m}$ mesh filter. Cell suspension was incubated at $37{ }^{\circ} \mathrm{C}, 5 \% \mathrm{CO}_{2}$ for $48 \mathrm{~h}$ to let glial cells adhere to the culture flask before it was washed with PBS to remove excess of myelin and cell debris. Cultures were subsequently refreshed twice a week. Cultures reached confluence after 2-3 weeks.

Primary FCD astrocyte cultures were derived from a surgical human brain specimen obtained from a patient with FCD type IIA (age at surgery, 16 years; female; location, frontal; seizure frequency, thrice per week; duration of epilepsy, 11 years) undergoing epilepsy surgery at the Department of Pediatrics/Neurosurgery of the Medical University Vienna (Vienna, Austria). FCD astrocyte cultures were established in the same manner as described above for fetal cultures.

Secondary astrocyte cultures for experimental manipulation were established by trypsinizing confluent cultures and sub-plating onto poly-L-lysine (PLL; $15 \mu \mathrm{g} / \mathrm{ml}$, Sigma-Aldrich)-precoated 12- and 24-well plates (Costar, Cambridge, MA, USA; $5 \times 10^{4}$ cells/well in a 12-well plate for RNA isolation and PCR; $2.5 \times 10^{4}$ cells/well for immunocytochemistry). In the present study, astrocytes were used for analyses at passages 2-4.

Cell cultures were stimulated with human recombinant (r)IL-1 $\beta$ (PeproTech, Rocky Hill, NJ, USA; 10 ng/ $\mathrm{ml}$ ) or in some experiments with lipopolysaccharide (LPS; 100 ng/ml; Sigma-Aldrich, St. Louis, USA) for $24 \mathrm{~h}$. Treatment of FCD-derived astrocytes with rapamycin $(100 \mathrm{nM})$ was started $24 \mathrm{~h}$ before and continued during IL-1 $\beta$ stimulation. Cells were harvested $24 \mathrm{~h}$ after stimulation. Viability of human cell cultures was not influenced by the performed treatments (Additional file 3: Figure S3).

For immunofluorescent staining of cell cultures, sections were incubated with the primary antibodies for $\beta 1, \beta 1 \mathrm{i}, \beta 5$, or $\beta 5 \mathrm{i}$ for $1 \mathrm{~h}$ at RT, followed by $2 \mathrm{~h}$ of incubation at RT with Alexa Fluor ${ }^{\bullet}$ 568-conjugated antirabbit or Alexa Fluor ${ }^{\ominus} 488$-conjugated anti-mouse IgG (1:200, Molecular Probes, The Netherlands) together with Alexa Fluor ${ }^{\circledast} 488$ or 594 Phalloidin (1:200, Molecular Probes, Plaats, The Netherlands) for counterstaining actin filaments. Sections were mounted using VECTASHIELD with DAPI (Vector Laboratories Inc., Burlingame, CA, USA). Fluorescent microscopy was performed using a Leica Confocal Microscope TSC SP$8 \mathrm{X}$ (Leica, Son, the Netherlands) at $\times 40$ magnification (bidirectional X, speed $600 \mathrm{~Hz}$, pinhole $1.00 \mathrm{AU}$ ).

\section{RNA isolation and real-time quantitative PCR analysis} For RNA isolation, cell culture material was homogenized in Qiazol Lysis Reagent (Qiagen Benelux, Venlo, The Netherlands). Total RNA was isolated using the miRNeasy Mini kit (Qiagen Benelux, Venlo, The Netherlands) according to the manufacturer's instructions. The concentration and purity of RNA were determined at 260/ 280 nm using a NanoDrop 2000 spectrophotometer (Thermo Scientific, Wilmington, DE, USA). To evaluate $\beta 1, \beta 1 \mathrm{i}, \beta 5$ or $\beta 5 \mathrm{i}$, and IFN $\gamma$ mRNA expression, $200 \mathrm{ng}$ of cell-culture-derived total RNA was reverse-transcribed into cDNA using oligo dT primers. PCRs were run on a Roche LightCycler 480 thermocycler (Roche Applied Science, Basel, Switzerland) using the following primers: $\beta 1$ (forward: accagctcggtttccaca, reverse: cccggtatcgg taacacatc); $\beta 5$ (forward: gagtctcagtgatggtctgagc, reverse: actccatggcggaacttg); $\beta 1 \mathrm{i}$ (forward: accaaccggggacttacc, reverse: tcaaacactcggttcaccac); $\beta 5 \mathrm{i}$ (forward: ccctacc caccctgttt; reverse: cacccagggactggaaga); and IFN- $\gamma$ (forward: gcaagatcccatgggttgtgt; reverse: ctggctcagattg caggcata). Quantification of data was performed using the computer program LinRegPCR in which linear regression on the log (fluorescence) per cycle number data is applied to determine the amplification efficiency per sample $[31,32]$. The starting concentration of each specific product was divided by the geometric mean of the starting concentration of the reference genes (EF1 $\alpha$ and C1orf43), and this ratio was compared between groups.

\section{Statistical analysis}

Statistical analyses were performed with GraphPad Prism software (Graphpad Software Inc., La Jolla, CA, USA). To assess differences in immunoreactivity score between multiple groups, non-parametric Kruskal-Wallis followed with Mann-Whitney $U$ test was used. Correlations were assessed using Spearman's (rho) rank correlation test. For cell culture data, Mann-Whitney $U$ test was used to asses differences between different conditions. $P<0.05$ was assumed to indicate a significant difference.

\section{Results}

\section{Case material and histological features}

The clinical features of the cases included in this study are summarized in Table 1. All operated patients had a history of chronic pharmacoresistant epilepsy. In this study, we included patients with mild degree of cortical dysplasia (mMCDs; [33]). Age at surgery, seizure duration, and seizure frequency were not statistically different between patients with FCD II and MMCD in this cohort, as well as between the FCD IIa and FCD IIb cases included in our cohort. Accordingly to the international consensus classification system of FCD [21], FCD II represents isolated focal lesions with architectural and dysmorphic abnormalities (FCD IIa with 
dysmorphic neurons only; FCD IIb with dysmorphic neurons and balloon cells; Figs. 1, 2, 3, and 4c-e). TSC patients were younger compared to $\mathrm{mMCD}$ and FCD patients. All six TSC tubers displayed similar histopathological features, including loss of lamination, astrogliosis, dysmorphic neurons, and giant cells with pale eosinophilic cytoplasm ([34]; Figs. 1, 2, 3, and 4f, g).

Proteasome subunit expression in FCD and cortical tubers Expression of $\beta 1, \beta 1 \mathrm{i}, \beta 5$, and $\beta 5 \mathrm{i}$ was observed in FCD, cortical tubers, and mMCD specimens (Figs. 1, 2, 3, and 4; Additional file 2: Figure S2 and Additional file 4: Figure
S4). We observed differences in the expression level as well as in the cell-specific and subcellular distribution of the different subunits (Table 3).

\section{Constitutive proteasome catalytic subunit $\beta 1$ and $\beta 5$}

Moderate expression of $\beta 1$ and $\beta 5$ subunits was observed in human control cortical specimens (Figs. 1a, b and 3a, b; Table 3). Nuclear neuronal expression was detected for $\beta 5$ in MCD specimens (Table 3; Additional file 4: Figure S4E); whereas only cytoplasm expression was detected in specimens from patients with Alzheimer's disease for both subunits (Additional file 4: Figure S4B, F).

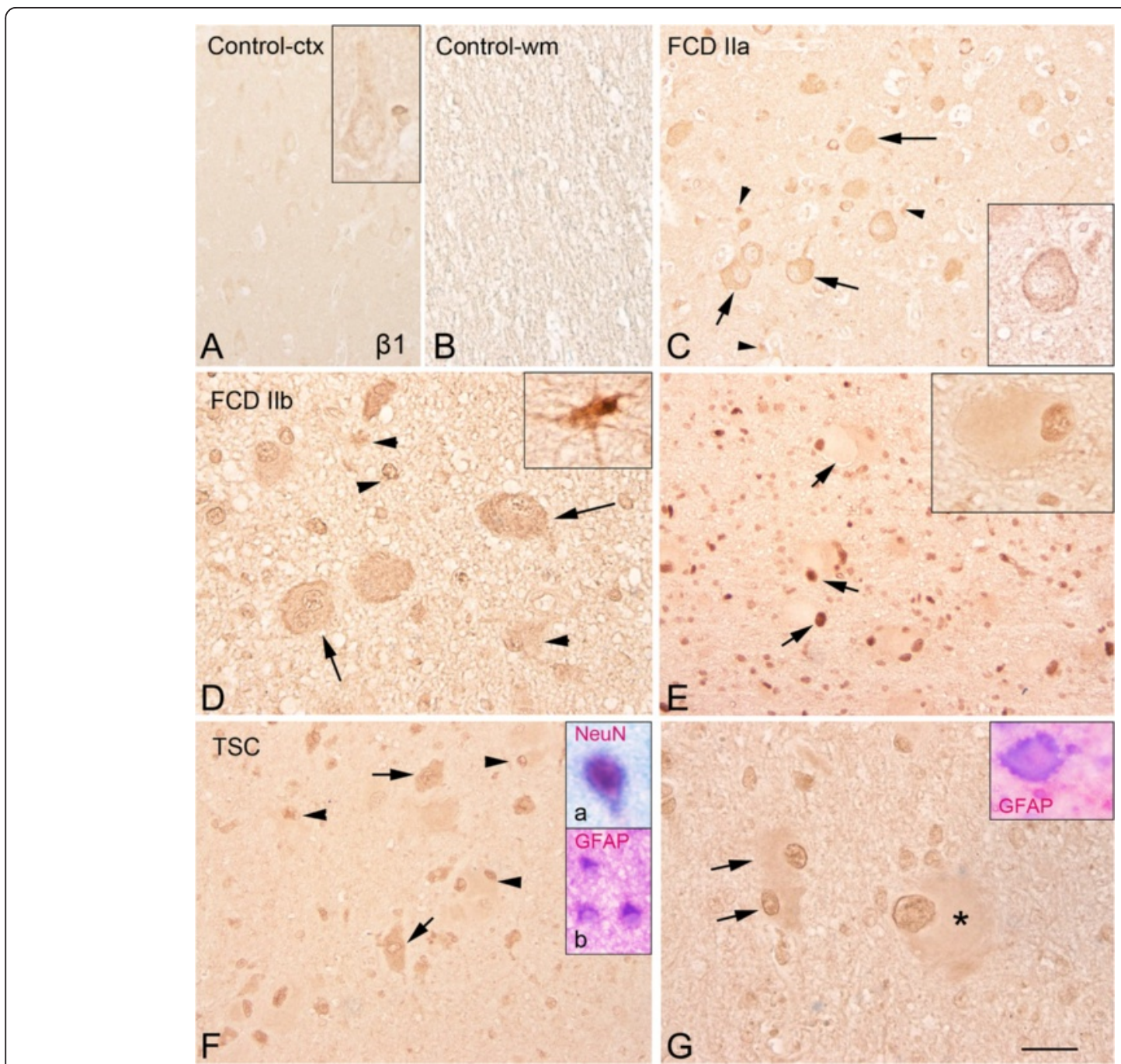

Fig. 1 B1 proteasome subunit immunoreactivity in control, focal cortical dysplasia (FCD) type lla, FCD type Illb, and tuberous sclerosis complex (TSC). Panels $\mathbf{a}, \mathbf{b}$ (control) show weak immunoreactivity (IR) in both the cortex (a insert: neuron with weak expression of $\beta 1$ subunit) and white matter (b not-detectable glial expression). Panel c (FCD Ila) shows positive dysmorphic neurons (arrows; insert: high magnification) and glial cells (arrow heads). Panels $\mathbf{d}-\mathbf{e}$ (FCD Ilb) show several $\beta 1$ positive cells within the cortex (d) and white matter (e), including the dysmorphic neurons (arrows in $\mathbf{d}$ ), glial cells (arrow heads and insert in $\mathbf{d}$ ) and balloon cells (arrows in e; prominent nuclear expression; insert: high magnification). Panels $\mathbf{f}-\mathbf{g}$ (TSC tuber): $\beta 1$ subunit expression is observed within the tuber in dysmorphic neurons (arrows in $\mathbf{f}$; insert a: co-localization with the neuronal marker NeuN; insert b, co-localization with GFAP), glial cells (arrow heads in $\mathbf{f}$ ) and in giant cells (asterisk (g); insert: co-localization with GFAP). Additional examples of the different cell types at higher magnification in separate specimens. The inserts within panels show imagines of the different cells types at higher magnification in separate specimens. Scale bar in G: A-C, E-F: $80 \mu \mathrm{m} ; \mathrm{D}-\mathrm{G}: 40 \mu \mathrm{m}$ 

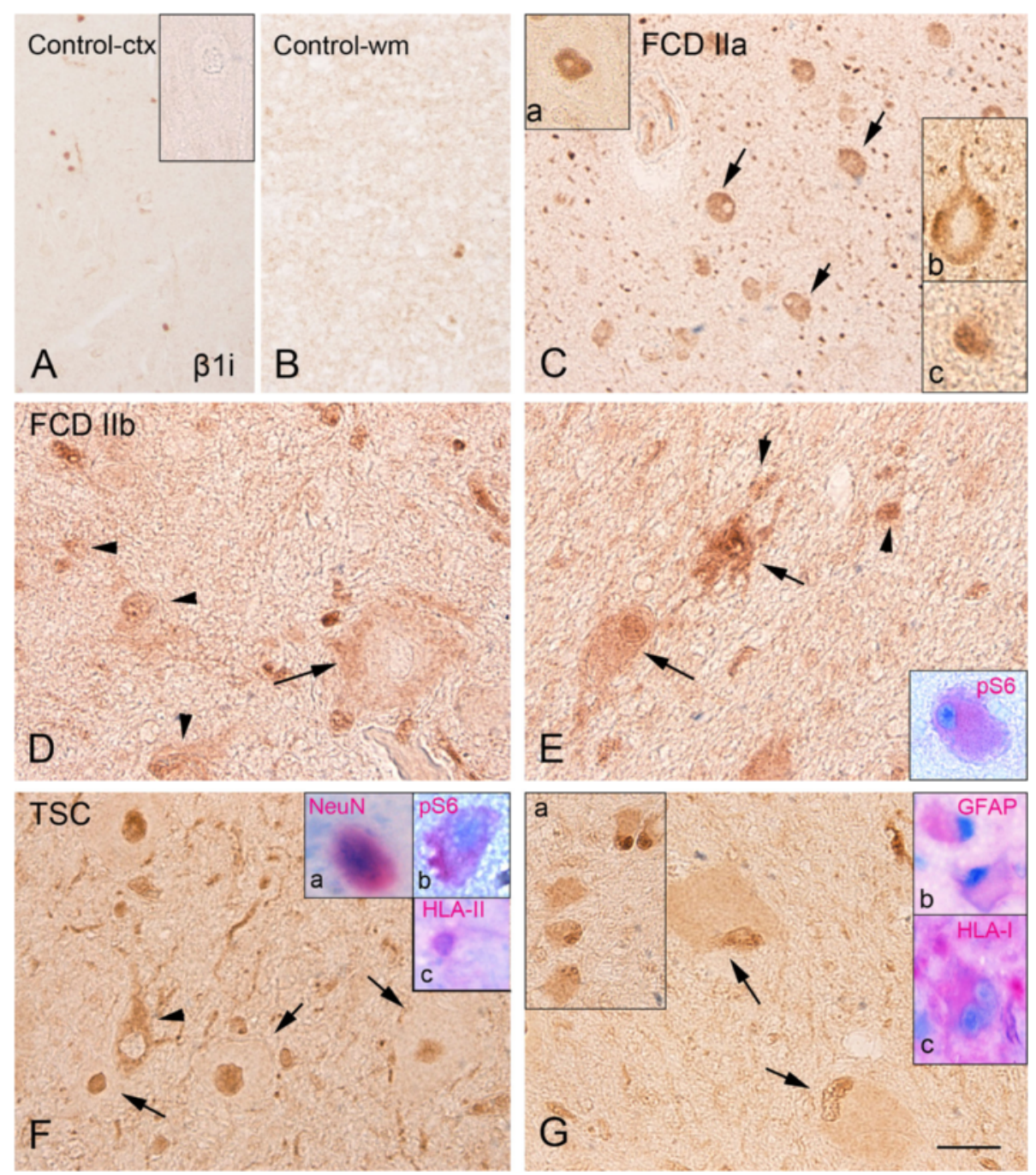

Fig. 2 31i proteasome subunit immunoreactivity in control, focal cortical dysplasia (FCD) type lla, FCD type Ilb, and tuberous sclerosis complex (TSC). a, b Control cortex (a) and with matter (b) with weak $\beta 1$ i expression (insert in a: negative neuron, high magnification). Panel $\mathbf{c}$ (FCD lla) shows strong expression within the dysplastic region with positive dysmorphic neurons (arrows; inserts: a nuclear expression; $\mathbf{b}$ cytoplasmic expression) and glial cells (insert in c). Panels $\mathbf{d}-\mathbf{e}$ (FCD Ilb) show several $\beta 1$ i-positive cells within the cortex (d) and white matter (e), including dysmorphic neurons (arrow in $\mathbf{d}$ ), glial cells (arrow heads $\mathbf{d}$ and $\mathbf{e}$ ), and balloon cells (arrows in $\mathbf{e}$; nuclear and cytoplasmic expression; insert: co-localization with the pS6). Panels $\mathbf{f}, \mathbf{g}$ (TSC tuber): $\beta 1$ i subunit expression is observed within the tuber in dysmorphic neurons ( $\mathbf{f}$ arrows, nuclear expression; arrow head, cytoplasmic expression; insert $\mathbf{a}$ in $\mathbf{f}$ : co-localization with the neuronal marker NeuN; insert $\mathbf{b}$ in $\mathbf{f}$ : co-localization with the pS6; insert c: co-localization with HLA-II), glial cells (insert $\mathbf{b}$ in $\mathbf{g}$ ), and in giant cells (arrows in $\mathbf{g}$; insert $\mathbf{b}$ : co-localization with GFAP; insert c: co-localization with $\mathrm{HLA}-\mathrm{I}$ ). The inserts within the panels show images of the different cell types at higher magnification in separate specimens. Scale bar in $\mathbf{g : ~ a - c : ~} 80 \mu \mathrm{m} ; \mathbf{d}-\mathbf{g}: 40 \mu \mathrm{m}$

Increased expression of both constitutive subunits was observed in FCD and TSC specimens (Figs. 1c-g and 3c-g; Table 2). In the large majority of FCD and TSC cases, $\beta 1$ IR was detected in the cytoplasm and nucleus of neuronal and glial cells (Fig. 1c-g; Table 3). $\beta 1$ was also detected in the balloon (FCD Ilb; Fig. 1e) and giant cells (TSC; Fig. 1g). FCD and TSC specimens displayed also strong $\beta 5$ IR with prominent nuclear expression in both neuronal and glial cells, as well as in the balloon (FCD IIb) and giant cells (TSC; Fig. 3c-g; Table 3). A similar pattern was detected in the postmortem TSC case; double-labeling experiments confirmed the co-localization with astroglial and neuronal markers within the dysplastic area for both subunits in FCD and TSC specimens (Figs. 1f-g and 3g).

\section{Immunoproteasome subunits $\beta 1 i$ and $\beta 5 i$}

In the large majority of control (Figs. $2 \mathrm{a}, \mathrm{b}$ and $4 \mathrm{a}, \mathrm{b}$ ) and MMCD (Additional file 4: Figure S4C, G) specimens, the immunoproteasome subunits $\beta 1 \mathrm{i}$ and $\beta 5 \mathrm{i}$ were under the detection levels in both neuronal and glial cells (Table 3). $\beta 1 \mathrm{i}$ and $\beta 5 \mathrm{i}$ were consistently high in FCD and TSC specimens (Table 3; Additional file 2: Figure S2) 

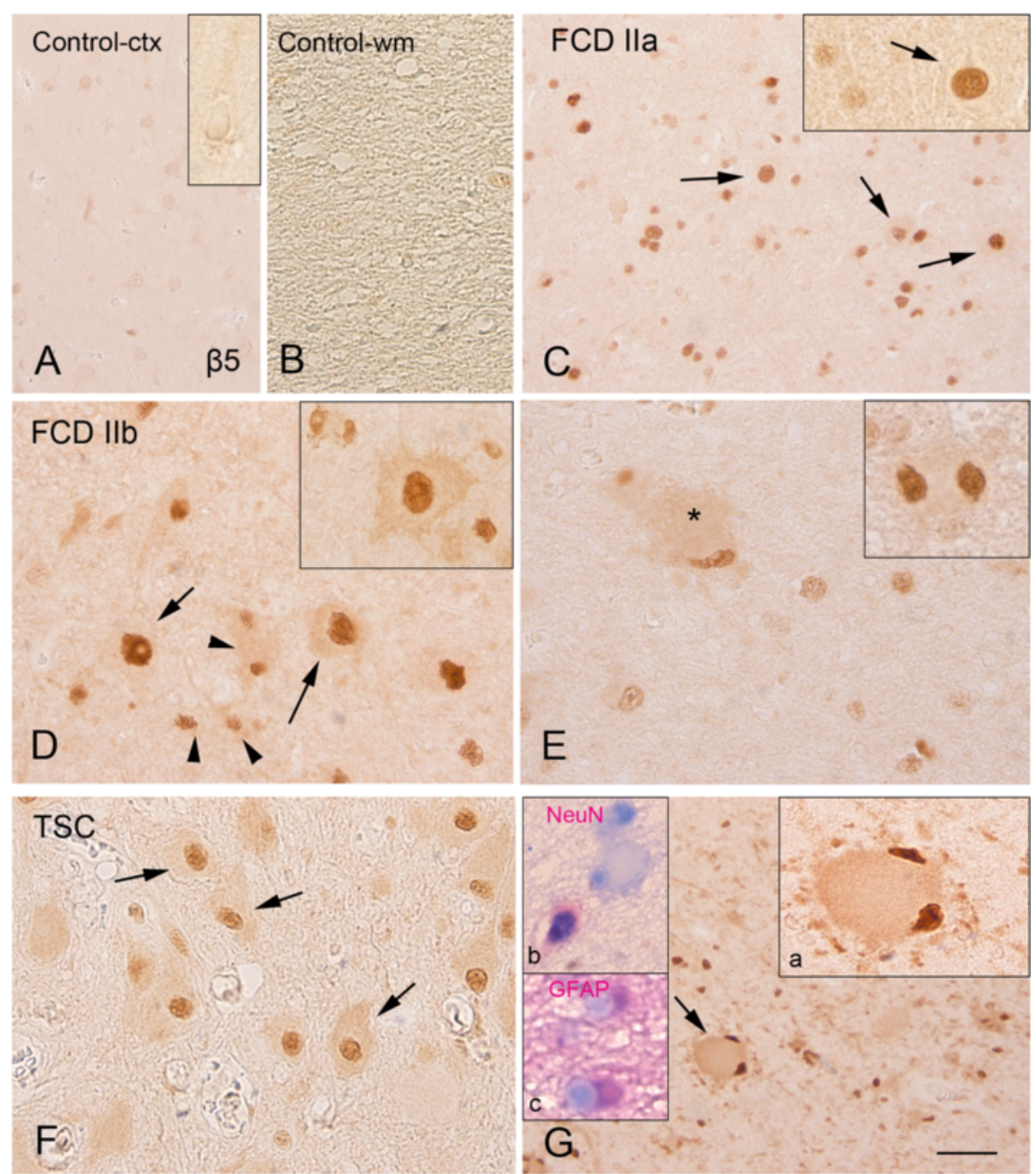

Fig. 335 proteasome subunit immunoreactivity in control, focal cortical dysplasia (FCD) type lla, FCD type llb, and tuberous sclerosis complex (TSC). Panels a and $\mathbf{b}$ : (control) show the weak immunoreactivity in both the cortex (a insert: neuron) and white matter (b not detectable glial expression). Panel c (FCD Ila) shows positive dysmorphic neurons (arrows; insert: high magnification, nuclear expression). Panels $\mathbf{d}$ and e (FCD Illb) show several $\beta 5$ positive cells within the cortex (d) and white matter (e), including dysmorphic neurons (arrows in $\mathbf{d}$ and insert, nuclear and cytoplasmic expression), glial cells (arrow heads and insert in $\mathbf{d}$ ), and balloon cells (asterisk in $\mathbf{e}$; insert: high magnification, with prominent nuclear expression). Panels $\mathbf{f}$ and $\mathbf{g}$ (TSC-tuber): $\beta 5$ subunit expression is observed within the tuber in dysmorphic neurons (arrows in $\mathbf{f}$; insert b in panel $\mathbf{g}$ : co-localization with the neuronal marker $\mathrm{NeuN}$; insert $\mathbf{c}$ in panel $\mathbf{g}$, co-localization with GFAP) and in giant cells (arrow in $\mathbf{g}$ and insert $\mathbf{a}$; insert $\mathbf{b}$ : co-localization with NeuN; insert c: expression in glial cells, co-localization with GFAP). The inserts within panels show images of the different cell types at higher magnification in separate specimens. Scale bar in $\mathbf{g}: \mathbf{a}-\mathbf{c}, \mathbf{g}: 80 \mu \mathrm{m} ; \mathbf{d}-\mathbf{f}: 40 \mu \mathrm{m}$

with strong cytoplasmic and nuclear IR in neuronal and glial cells, in both surgical postmortem TSC specimens (whereas only cytoplasmic expression was detected in glial cells in specimens from patients with Alzheimer's disease for both $\beta 1 \mathrm{i}$ and $\beta 5 \mathrm{i}$ subunits; Additional file 4: Figure S4D, H). A similar pattern with strong expression in FCD and TSC specimens was observed using in situ hybridization (Additional file 5: Figure S5). Doublelabeling experiments confirmed the co-localization with astroglial and neuronal markers, as well as with major histocompatibility complex (MHC) class I (HLA-I; in few balloon/giant cells and in dysmorphic neurons) within the dysplastic area for both subunits in FCD and TSC specimens (Figs. 2 and 4f, g). In regions with prominent activation of microglia, IR for both $\beta 1 \mathrm{i}$ and $\beta 5 \mathrm{i}$ was also observed in cells of the microglia/macrophage lineage (HLA-II; Figs. 2 and 4). The balloon (FCD IIb; Fig. 2e) and giant cells (TSC; Fig. 4g) displayed $\beta 1 \mathrm{i}$ and $\beta 5 \mathrm{i}$ IR as well (Table 2). Co-localization was observed for both $\beta 1 \mathrm{i}$ and $\beta 5 \mathrm{i}$ with pS6 (Figs. 2 and 4$)$. $\beta 1 \mathrm{i}$ and $\beta 5 \mathrm{i}$ expression in neurons was positively associated with $\mathrm{pS} 6$ expression within our MCD 


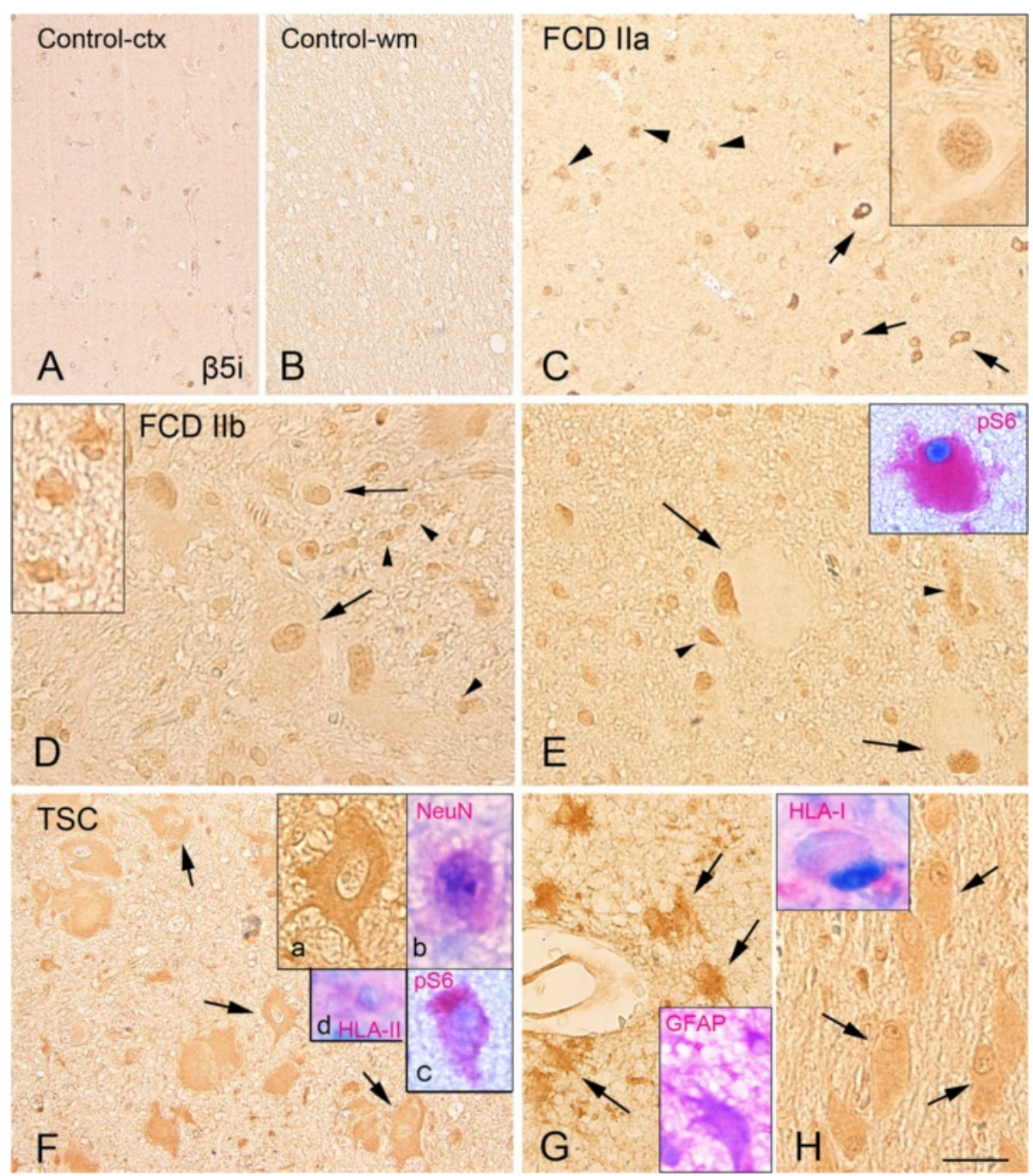

Fig. 4 35i proteasome subunit immunoreactivity in control, focal cortical dysplasia (FCD) type lla, FCD type Ilb, and tuberous sclerosis complex (TSC). Panels $\mathbf{a}$ and $\mathbf{b}$ : control cortex (a) and with white matter (b) with weak $\beta 5 i$ expression. Panel $\mathbf{c}$ (FCD Ila) shows expression within the dysplastic region with positive dysmorphic neurons (arrows and insert, nuclear expression) and glial cells (arrow heads). Panels $\mathbf{d}$ and $\mathbf{e}$ (FCD Ilb) show several $\beta 5$ i-positive cells within the cortex (d) and white matter (e), including dysmorphic neurons (arrow in $\mathbf{d}$ ), glial cells (arrow heads $\mathbf{d}$ and $\mathbf{e}$; insert in $\mathbf{d}$ ), and balloon cells (arrows in $\mathbf{e}$; insert: co-localization with pS6). Panels $\mathbf{f}$, and $\mathbf{g}$ (TSC-tuber): strong $\beta 5$ i subunit expression is observed within the tuber in dysmorphic neurons (f arrows and inserts $\mathbf{a}$ and $\mathbf{b}$; $\mathbf{b}$ co-localization with the neuronal marker NeuN; $\mathbf{c}$ co-localization with the pS6; $\mathbf{d}$ co-localization with HLA-II), glial cells (arrows in $\mathbf{g}$; insert in $\mathbf{g}$, co-localization with GFAP), and in giant cells (arrows in $\mathbf{h}$; insert: co-localization with HLA-I). The inserts within the panels show images of the different cell types at higher magnification in separate specimens. Scale bar in $\mathbf{h}$ : a-c $80 \mu \mathrm{m}$; $\mathbf{d}-\mathbf{h} 40 \mu \mathrm{m}$

cohort ( $\beta 1 \mathrm{i}$ cytoplasm, $r=0.5905, p=0.030 ; \beta 1 \mathrm{i} \mathrm{nu}-$ cleus, $r=0.6244, p=0.0014 ; \beta 5 \mathrm{i}$ cytoplasm, $r=0.4510$, $p=0.0065)$. A positive correlation was detected between $\beta 1 \mathrm{i}$ and $\beta 5 \mathrm{i}$ expression in neurons and glial cells and IL-1 $\beta$ IRS within the dysplastic region (neuronal $\beta 1 \mathrm{i}$ cytoplasm, $r=0.4287, \quad p=0.0413$; neuronal $\beta 1 \mathrm{i}$ nucleus, $r=0.5090, p=0.0131$; glia $\beta 1 \mathrm{i}$ cytoplasm, $r=$ 0.5298, $p=0.0093$; glia $\beta 1 \mathrm{i}$ nucleus, $r=0.6091, p=0.0003$; neuronal $\beta 5 \mathrm{i}$ cytoplasm, $r=0.7322, p=<0.001$; glia $\beta 5$ i cytoplasm, $r=0.7005, p=<0.001$; glia $\beta 5$ i nucleus, $r=0.4210, p=0.0455)$.
Immunoproteasome subunit expression and clinical features We found no statistically significant association between the IRS of $\beta 1, \beta 1 i, \beta 5$ or $\beta 5 i$, and clinical features, such gender, age at surgery, location of the lesion, or duration of epilepsy. However, a positive correlation was observed between nuclear glial and neuronal subunit expression and the pre-operative seizure frequency $(\beta 1$ and $\beta 1 \mathrm{i}$ neuron $\tau=0.639$ and $\tau=0.633, p<0.001 ; \beta 1$ and $\beta 1$ i glia $\tau=0.479, p=0.005$ and $\tau=0.65, p<0.001 ; \beta 1$ and $\beta 1 \mathrm{i}$ neuron $\tau=0.550, p=0.004$ and $\tau=0.417, p=0.016 ; \beta 1$ and $\beta 1$ i glia $\tau=0.570, p=0.001 ; \tau=0.586, p=0.001$ ). 


\section{Regulation of immunoproteasome subunit expression in human glial cells in culture}

Since IL-1 $\beta$ is known to be strongly upregulated in FCD and TSC human brain specimens [27, 34, 35] and to play a key pathogenic role in human epilepsy (for review, see [20,36]; we also investigated whether this inflammatory cytokine could play a role in the regulation of the expression and cellular localization of immunoproteasome subunits. qPCR analysis of astrocyte-enriched human fetal cell cultures demonstrated that exposure to IL- $1 \beta$ did not modify the expression of the constitutive subunits (Fig. 5a,d) but did consistently increase the expression of both immunoproteasome subunits $\beta 1 \mathrm{i}$ and $\beta 5 \mathrm{i}$ (Fig. $5 \mathrm{~b}, \mathrm{e}$ ), increasing the $\beta 1 / \beta 1 \mathrm{i}$ and $\beta 5 / \beta 5 \mathrm{i}$ ratios (Fig. $5 \mathrm{c}, \mathrm{f}$ ). Treatment with LPS, also a potent inducer of the immune response, gave comparable results (Fig. 5). Exposure to IL-1 $\beta$ and LPS did not significantly affect the expression of IFNy in these cultures. Immunohistochemistry showed a translocation of the $\beta 1 \mathrm{i}$ and $\beta 5 \mathrm{i}$ subunits, shifting from cytoplasmic to perinuclearnuclear expression following IL-1 $\beta$ treatment (Fig. 6d, h).

\section{Effects of rapamycin on proteasome subunit expression in FCD II-derived astrocytes}

Since both FCD II and TSC are associated with constitutive activation of the mTOR pathway $[19,20]$, we investigated whether the canonical and allosteric mTOR kinase rapamycin modulates the immunoproteasome in cell cultures derived from FCD II specimens. Western blot analysis confirmed that $100 \mathrm{nM}$ rapamycin reduced the phosphorylation of S6 (pS6) in human astrocytes, an indicator of mTOR activation (Additional file 3: Figure S3). Pretreatment with $100 \mathrm{nM}$ rapamycin reduced the mRNA expression of $\beta 1$ and $\beta 1 \mathrm{i}$ subunits under both unstimulated and stimulated conditions (Fig. 7a, b). $\beta 5$ and $\beta 5 \mathrm{i}$ expression was reduced by rapamycin in the presence of IL-1 $\beta$ (Fig. 7c, d). Immunocytochemical analysis of these FCD cells confirmed the negative modulation of proteasome subunits by rapamycin (Fig. 8).

\section{Discussion}

The present study reports in detail the expression pattern and cellular localization of the constitutive and immunoproteasome subunits in FCD II and TSC
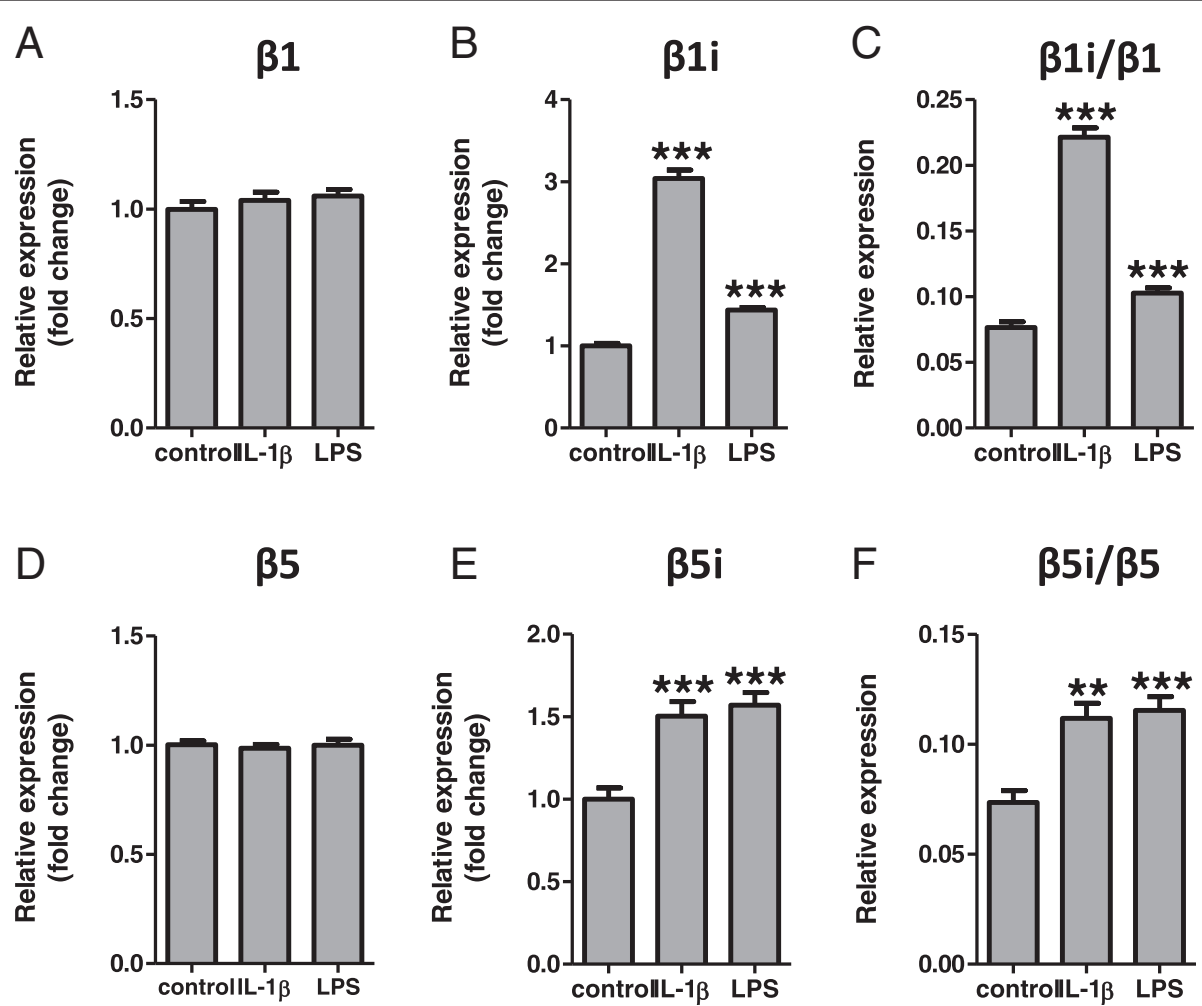

Fig. 5 Effects of IL-1 $\beta$ and LPS stimulation on immunoproteasome subunit expression in cell culture. Quantitative real-time PCR of proteasome expression in human fetal astrocytes after the $24 \mathrm{~h}$ exposure to $\mathrm{IL}-1 \beta(10 \mathrm{ng} / \mathrm{ml})$ or LPS $(100 \mathrm{ng} / \mathrm{ml})$. $\mathbf{a}, \mathbf{b}$, d, e Stimulation with IL-1 $\beta$ or LPS increased expression of the $\beta 1$ i (b) and the $\beta 5$ i (e) subunits compared to control, but not of the constitutive $\beta 1$ (a) and $\beta 5$ (d) subunits. c, $\mathbf{f}$ Stimulation with either IL-1 $\beta$ or LPS increased the $\beta 1 \mathrm{i} / \beta 1$ (c) and the $\beta 5 \mathrm{i} / \beta 5$ (f) ratios. Data are expressed relative to the levels observed in untreated cells and are mean $\pm \operatorname{SEM}(n=5) .{ }^{* *} p<0.01$, ${ }^{* * *} p<0.001$ compared to control, Mann-Whitney $U$ test 


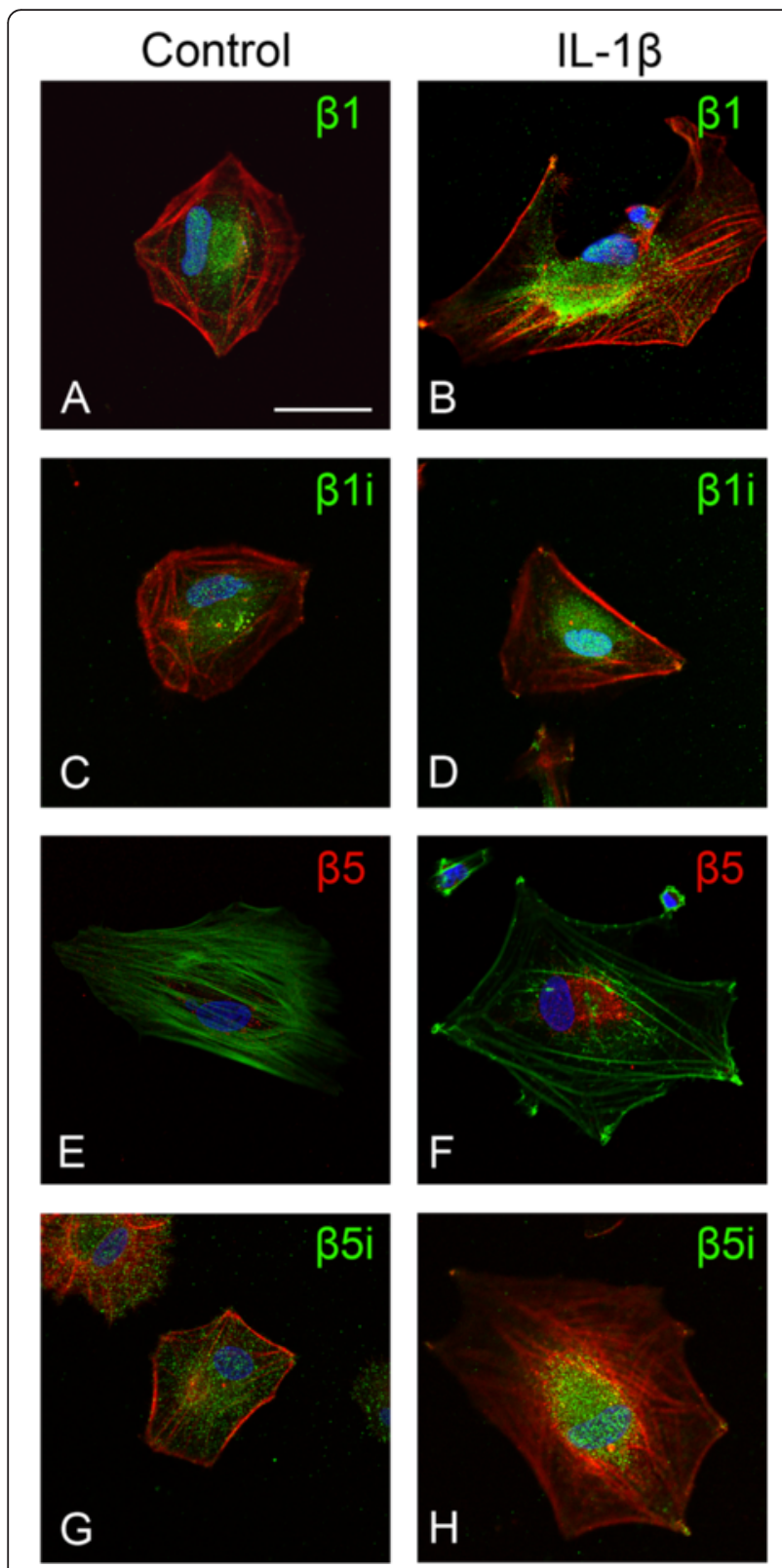

Fig. 6 Effects of IL-1 $\beta$ stimulation on proteasome subunit expression in astrocytes in cell culture. Expression of $\beta 1$ ( $\mathbf{a}$ and $\mathbf{b}$; green), $\beta 1 \mathrm{i}$ (c and $\mathbf{d}$; green), $\beta 5$ (e and $\mathbf{f} ;$ red), and $\beta 5 i$ (g and $\mathbf{h}$; green) in unstimulated human fetal astrocytes (left panels) and in astrocytes after exposure to IL-1 3 ( $24 \mathrm{~h} ; 10 \mathrm{ng} / \mathrm{ml}$, right pane/s); increased expression of all subunits was observed. A translocation of particularly the $\beta 1 i$ and $\beta 5 i$ subunits, shifting from cytoplasmic to perinuclear-nuclear expression following $\mathrm{IL}-1 \beta$ treatment was observed. Cells were counterstained with phalloidin (actin filaments; red in $\mathbf{a}-\mathbf{d}$ and $\mathbf{g}-\mathbf{h}$, green in $\mathbf{e}$ and $\mathbf{f}$ ) and diamidino-2phenylindole, DAPI (nuclei; blue). Scale bar in a: $15 \mu \mathrm{m}$

cortical tubers and mMCD. The cell-specific distribution of proteasome subunits in relation with the epileptogenicity of these developmental lesions as well as their regulation in human astrocytes is discussed in the following paragraphs.
Proteasome subunits expression in malformations of cortical development: prominent expression in FCD II and TSC

Our data show prominent expression of both constitutive and immunoproteasome subunits in MCD, such as FCD and TSC, associated with the mTOR pathway. In all the FCD II and TSC specimens examined, the IR for $\beta 1, \beta 1, \beta 5$, and $\beta 5 \mathrm{i}$ was increased within the dysplastic regions where prominent gliosis and the presence of dysmorphic neurons and balloon or giant cells (in FCD IIb and TSC, respectively) was observed. Constitutive and particularly immunoproteasome subunits displayed increased expression compared to control but also compared to mMCD specimens from patients with chronic epilepsy. These results indicate that increased expression of proteasome subunits is not simply an effect of seizure activity; moreover, the duration of epilepsy in mMCD cases did not differ from FCDs and was even longer compared to TSC cases. However, a positive correlation was observed between nuclear glial and neuronal proteasome subunit expression and the pre-operative seizure frequency. We acknowledge limitations to the interpretation of these results; therefore, an evaluation of the real biological contribution of proteasome subunit expression to seizure generation and frequency deserves further investigation in experimental models.

Several proteasome subunits show nuclear localization signaling [37], and previous studies in the human brain indicate that proteasomes are expressed in both cytoplasm and nuclei of different cell types, including glial and neuronal cells $[24,38]$. Immunoproteasome expression restricted to nuclei of astrocytes has been reported in the brain after an infection with lymphocytic choriomeningitis virus, suggesting involvement of the nuclear envelope in the compartmentalization of immature proteasome precursors [39]. Whether the nuclear proteasome subunits represent (as suggested by Kremer et al. [39]) immature proteasome precursors or are proteolytically active remains still to be investigated. The nuclear proteasome subunit accumulation may reflect the induction of the proteasome system under conditions associated with cell injury and inflammation with the possibility of nucleo-cytoplasmic transfer in cells, as glial cells, undergoing cell division or during apoptosis [37]. However, the $\beta 1 \mathrm{i}$ subunit in the nuclear-enriched fraction has also been detected in its catalytically active form [40], and several studies indicate a possible functional role of the immunoproteasome in transcriptional regulation [41-43]. The expression pattern, either nuclear or cytoplasmic proteasome expression, can be influenced by the type and duration of fixation [37]. However, similar pattern was observed in surgical and postmortem TSC brain tissue. 

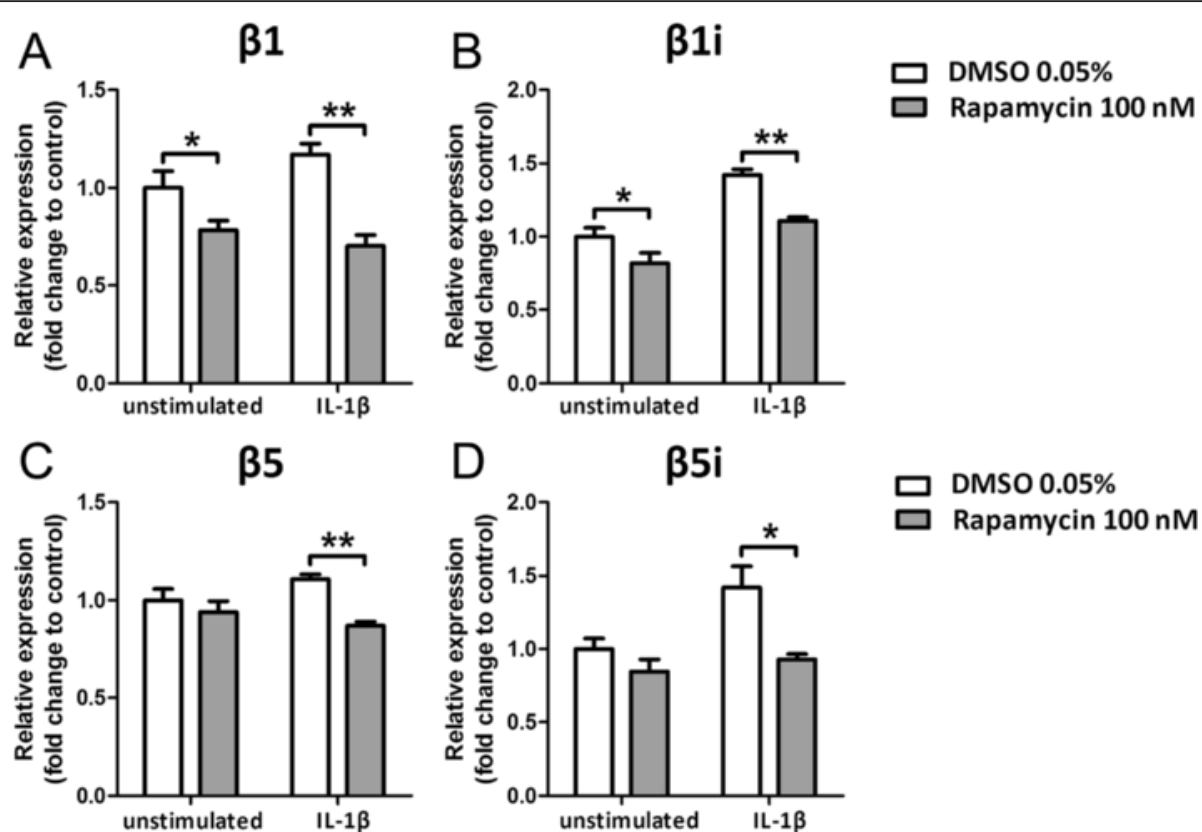

Fig. 7 Effects of rapamycin on proteasome subunit expression in astrocytes derived from FCD type II. Quantitative real-time PCR of proteasome expression in human FCD cells after $48 \mathrm{~h}$ treatment with $100 \mathrm{nM}$ rapamycin, under basal and stimulated (IL-1 $\beta 10 \mathrm{ng} / \mathrm{ml}$ ) conditions. $\mathbf{a}, \mathbf{b}$ Treatment with rapamycin decreased the expression of $\beta 1$ (a) and $\beta 1$ i (b) subunit, both in the basal and under stimulated conditions. $\mathbf{c}$, $\mathbf{d}$ Treatment with rapamycin decreased the expression of $\beta 5$ (c) and $\beta 5 i$ (d) subunit under stimulated, but not in basal conditions. Data are expressed relative to the levels observed in untreated cells and are mean $\pm \operatorname{SEM}(n=5) .{ }^{*} p<0.05,{ }^{* *} p<0.01$ compared to control, Mann-Whitney $U$ test

One of the major regulatory factors of immunoproteasome induction is inflammation [43, 44]. Several studies confirmed the occurrence of complex inflammatory changes, involving both glial and neuronal cells, and the activation of the IL-1 $\beta$ pathway, particularly in FCD II and TSC [20, 34, 35, 45-48]. Thus, the pro-inflammatory environment may contribute to the activation of the proteasome system, particularly to the induction and expression of the immunoproteasome subunits. Accordingly, our in vitro studies in human astrocytes and FCD cultures indicate that IL-1 $\beta$ treatment increases the induction of, in particular, the immunoproteasome subunits $\beta 1 \mathrm{i}$ and $\beta 5 \mathrm{i}$, with the increase of their perinuclear-nuclear localization. This observation supports the role of astrocytes as targets of regulation of the immunoproteasome under various conditions associated with the activation of the IL-1 $\beta$ pathway [16] and indicates that proinflammatory cytokines, other than IFN $\gamma$, may regulate immunoproteasome expression. Activation of inflammatory pathways, including IL- $1 \beta$, may also play a role in the regulation of immunoproteasome expression in other cell types, such as neurons. Accordingly, we found a positive correlation between the expression of immunoproteasome subunits in both glial and neuronal cells and the expression of IL- $1 \beta$ within the dysplastic area in FCD II and in TSC specimens. Moreover, increasing evidence supports the role of the immunoproteasome in the activation of the NF-kB pathway, modulation of pro-inflammatory cytokine production, and oxidative stress response $[9,43,49-52]$. Induction of the $\beta 5 \mathrm{i}$ subunit has also been shown in vivo following activation of the Toll-like receptor 4 (TLR4)-mediated NF-kB signaling pathway by LPS [53]. Thus, we may speculate about the existence of a reinforcing feedback loop between NF-kB pathway and the immunoproteasome system, which may play a crucial role in perpetuating the pro-epileptogenic inflammatory response in epilepsy. Interestingly, Mishto et al. [18] provide additional experimental evidence of the regulation of $\beta 5 i$ subunit by TLR4 signaling in epileptogenic tissue.

The immunoproteasome is known to improve MHC class I (MHC-I) antigen presentation and has been suggested to have a central function at the interface between the innate and adaptive immune system (reviewed in [11]). Interestingly, FCD II and TSC specimens are characterized by prominent activation of both innate and adaptive immune responses (for review, see $[20,36]$ ). Moreover, recent studies provide evidence of an upregulation of MHC-I, involving also balloons/giant cells and neurons, in both FCD II and TSC specimens [54].

FCD II and TSC cases are characterized by architectural or cellular changes associated with mTOR pathway activation [20, 21]. The innate and adaptive immune responses have also been shown to be influenced by the mTOR pathway [55-57]. Moreover, the mTOR complex 1 (mTORC1) has been identified as a key regulator of 


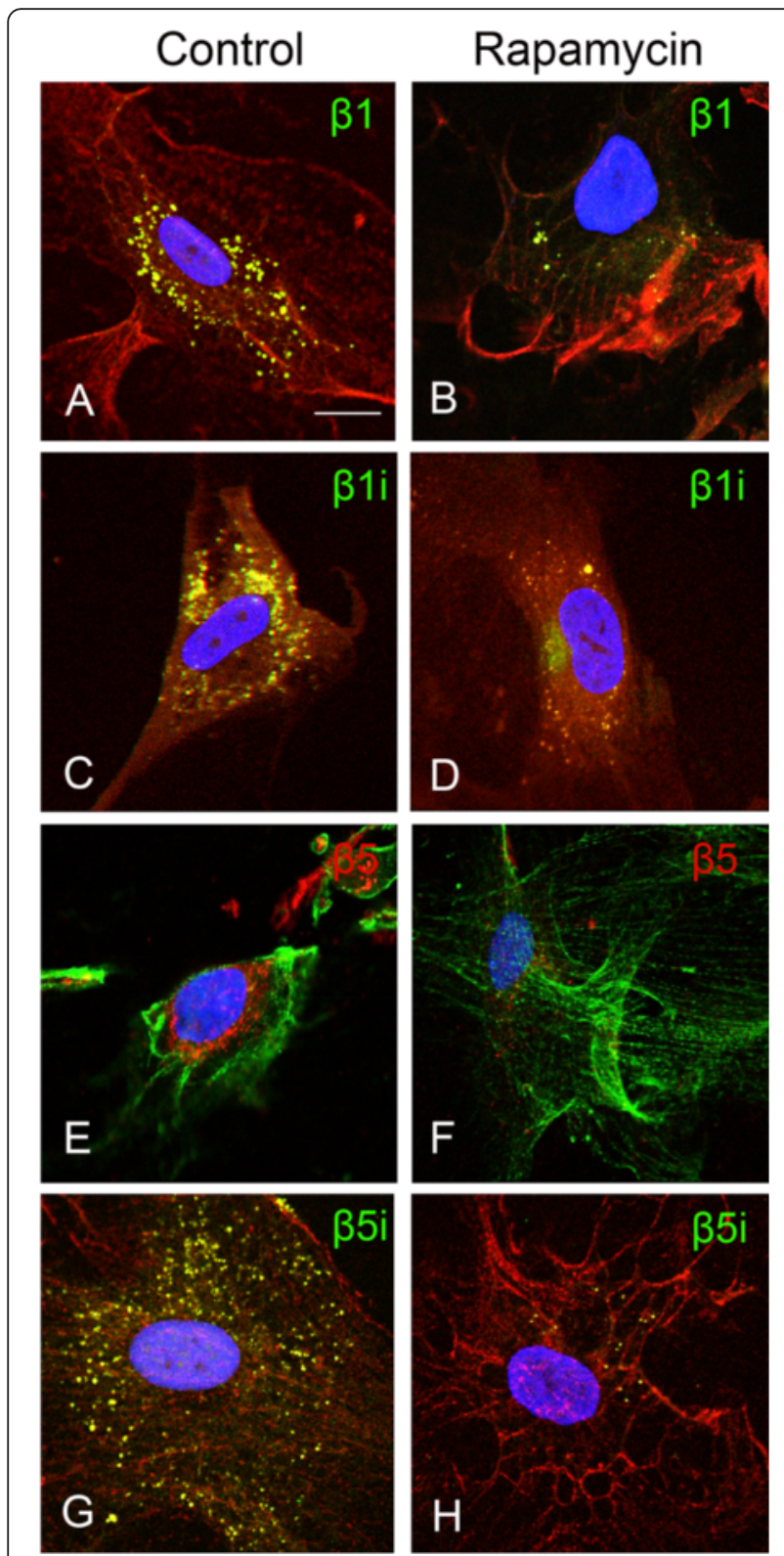

Fig. 8 Effects of rapamycin treatment on proteasome subunit expression in FCD type II derived cells. Expression of $\beta 1$ ( $\mathbf{a}$ and $\mathbf{b}$; green), $\beta 1 i$ (c and $\mathbf{d}$; green), $\beta 5$ (e and $\mathbf{f}$; red), and $\beta 5 i$ ( $\mathbf{g}$ and $\mathbf{h}$; green) in untreated FCD cells (left panels) and in FCD cells after $48 \mathrm{~h}$ of treatment with $100 \mathrm{nM}$ rapamycin (right pane/s). Expression of all subunits was decreased after treatment with rapamycin. Cells were counterstained with phalloidin (actin filaments; red in $\mathbf{a}-\mathbf{d}$ and $\mathbf{g}-\mathbf{h}$, green in $\mathbf{e}$ and $\mathbf{f}$ ) and diamidino-2-phenylindole, DAPI (nuclei; blue). Scale bar in a: $15 \mu \mathrm{m}$

autophagy [58, 59], a pathway which is defective in FCD II and TSC [60]. Increasing evidence indicates a strong relationship with tight coordination between the autophagy and the proteasome system [61]. Thus, we cannot exclude a role of $\mathrm{mTOR}$ in the regulation of the proteasome system, including immunoproteasome subunit expression. Accordingly, we observed a positive correlation between immunoproteasome subunit expression in neurons and pS6 expression, indicating the activation of the mTOR signal transduction pathway. The relationship between mTOR and proteasome system is also supported by the in vitro experiments showing that inhibition of the mTOR pathway by the potent allosteric mTORC1 inhibitor rapamycin was able to reduce the level of expression of inducible proteasome subunits in FCD-derived cells. This is in agreement with a recent study showing reduction of the immunoproteasome by rapamycin in $\mathrm{H} 9 \mathrm{c} 2$ cells as well as in mouse heart in vivo [62]. Evaluation of the possible effect of rapamycin on the expression of the brain immunoproteasome in vivo deserves further studies and is presently under investigation [63].

\section{Immunoproteasome inhibition as therapeutic strategy?}

An example of the possible use of inhibition of the immunoproteasome as therapeutic strategy in epilepsy is represented by the study of Mishto and colleagues [18] in which specific inhibition of the $\beta 5 \mathrm{i}$ subunit by ONX0914 [64] resulted in prevention, or significant delay, of 4-aminopyridine-induced seizure-like events in acute rat hippocampal/entorhinal cortex slices, particularly in slices of epileptic rats. Clinically approved proteasome inhibitors targeting the catalytic activity of both the constitutive proteasome and the immunoproteasome have been already used in hematological malignancies [65-67]. New-generation small molecules specifically targeting the immunoproteasome are under clinical development and have been already evaluated in a large variety of animal models of autoimmune diseases and proposed as novel therapeutic approaches for patient with multiple sclerosis, as well as in neurodegenerative diseases (for reviews, see [16, 68, 69]).

However, recently alternative functions for the immunoproteasome have also been considered, suggesting that the induction of the immunoproteasome may also play a role in neuronal protection and repair after injury, contributing to the preservation of cell viability upon cytokine-induced oxidative stress $[49,70,71]$, which is known to be increased within the TSC tubers [72]. In particular, evidence has been provided that the immunoproteasome plays a role in the clearance of damaged proteins accumulating upon inflammation or oxidative stress (for review, see [49]), which are also detected in TSC and FCD [73]. Accordingly, the formation of aggresome-like-induced structures and increased sensitivity to apoptosis has been reported in immunoproteasome deficiency in cells and in a murine inflammation model [49, 71]. Additional studies support alternative physiological function of the immunoproteasome subunits, including also cell proliferation, cell signaling, 
and synaptic remodeling (for review, see [49, 74, 75]). Thus, an effective therapeutic intervention based on the immunoproteasome has to take into consideration the preservation of the potential beneficial functions of its activation, particularly during brain development.

\section{Conclusions}

One important question is whether the activation of the immunoproteasome system in the brain tissue may per se be responsible for an increased susceptibility to seizure activity observed in FCD and TSC. As discussed above, experimental studies in the hippocampal/entorhinal cortex slices suggest that the pharmacological inhibition of the $\beta 5 i$ subunit may modulate seizure activity. Whether these findings can be translated to other experimental models, including models of FCD and TSC, deserves further investigation.

To conclude, our observations support the occurrence of a prominent deregulation of the proteasome system in MCD. In particular, the induction of immunoproteasome subunits in both glial and neuronal cells appears to be a feature of FCD II and TSC and may represent an important accompanying feature of the immune response in these developmental lesions. Therefore, understanding the role of the immunoproteasome in epilepsy-associated pathologies may have great importance in view of the development of new therapeutic strategies.

\section{Additional files}

Additional file 1: Figure S1. Representative immunoblot analysis of total homogenates from $(n=3)$ surgical hippocampal specimens; $\beta$-subunits ( $\beta 1, \sim 25 \mathrm{kDa} ; \beta 1 \mathrm{i}, \sim 22 \mathrm{kDa} ; \beta 5, \sim 25 \mathrm{kDa} ; \beta 5 \mathrm{i}, \sim 25 \mathrm{kDa} ; \beta$-actin $\sim 42 \mathrm{kDa}$ ). (JPG $134 \mathrm{~kb})$

Additional file 2: Figure $\mathbf{S 2}$. $\beta 1 i$ and $\beta 5 i$ intensity signal in control, mMCD, FCDII, and TSC. FCD: focal cortical dysplasia; TSC: tuberous sclerosis complex; mMCD: mild malformations of cortical development. (PPTX 61 kb)

Additional file 3: Figure S3. Effect of the different treatments on fetal astrocyte cell cultures. A: scatterplots of eFluor viability dye staining as analyzed by flow cytometry after different treatments. B: Quantification of viable cells based on eFluor viability staining. Neither treatment with IL-1 $\beta$ nor rapamycin negatively influenced viability of cell cultures. C: Western blot analysis showed effective reduction of phosphorylated 56 after $24 \mathrm{~h}$ of $100 \mathrm{nM}$ rapamycin treatment. FSC: forward scatter. (JPG $1420 \mathrm{~kb}$ )

Additional file 4: Figure S4. Proteasome subunit immunoreactivity ( $\beta 1$, $\beta 1 i \beta 5$, and $\beta 5 i)$ in mild $M C D(m M C D)$ and in Alzheimer' s disease (Alz). Panels $A, C, E$, and G: mMCD. A: low $\beta 1$ expression (insert: high magnification of a neuron, with weak nuclear expression). C: low $\beta 1$ i expression (insert: high magnification of a neuron). E: nuclear expression of $\beta 5$ (arrows; neuron in insert). G: low $\beta 5 i$ expression (neuron in insert). Panels B, D, F, and $\mathrm{H}$ (Alz; hippocampus). B: $\beta 1$ expression in neurons (CA1; arrows, cytoplasmic expression) and around amyloid plaques (arrow-heads); D: $\beta 1 \mathrm{i}$ expression in glial cells (arrows, cytoplasmic expression). F: low $\beta 5$ expression in neuronal cells (arrows). $\mathrm{H}$ : $\beta 5$ i expression in glial cells (arrows, cytoplasmic expression). Scale bar in B: A, C, F, and G: $80 \mu \mathrm{m} ; \mathrm{B}, \mathrm{D}$, and H: 40 m. (JPG $2799 \mathrm{~kb}$ )

Additional file 5: Figure S5. In situ hybridization of $\beta 1 i$ and $\beta 5 i$, proteasome subunit immunoreactivity in control, focal cortical dysplasia (FCD) type Ilb, and tuberous sclerosis complex (TSC). Panels A-D: control cortex $(A-C)$ and with matter $(B-D) ; \beta 1 i(A-B)$ and $\beta 5 i(C-D)$. Panels $E-F$ (FCD Ilb) and panels $C-G$ (TSC) shows strong expression within the dysplastic region with several positive dysmorphic neurons (arrows and inserts in $E(a)$ and F), giant cells (inserts in $G$ and $H(a)$ ), and glial cells

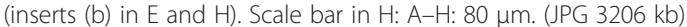

Additional file 6: Supplementary methods: flow cytometric analysis, in situ hybridization, Western blot analysis and image quantification. (DOC $46 \mathrm{~kb})$

\section{Acknowledgements}

We acknowledge the Bloemenhove Clinic (Heemstede, The Netherlands). We are grateful to A.M. Iyer and K.W. Geijtenbeek for technical assistance.

\section{Funding}

This work was supported by the European Union's Seventh Framework Programme (FP7/2007-2013) under grant agreement no. 602391 (project acronym EPISTOP; JVS, MF, TS, EA) and grant agreement no. 602102 (project acronym EPITARGET; EVV, EA); the Austrian Science Fund (FWF): project no. J3499 (AM), and the TSC Research Award 2015 from the German Tuberous Sclerosis Foundation (TS).

\section{Availability of data and materials}

All data generated or analyzed during this study are included in this published article (and in Additional file 1, 2, 3, 4, 5 and 6).

\section{Authors' contributions}

JS, DB, MZ, and JJA carried out the immunohistochemical analyses. JS performed the GPCR analysis. Western blot was performed by JS and DB and in situ hybridization by JJA. Analysis of the data was performed by JS, $\mathrm{DB}$, and $\mathrm{MZ}$. EV and $\mathrm{AM}$ contributed to the data analysis and interpretation. Cell culture experiments were performed by JS and TS. WS, PR, TC, JAA, MF, $\mathrm{TS}, \mathrm{AM}$, and EA helped with the selection and collection of the brain tissues. AE conceived the study and participated in its design and coordination together with EV and AM. JS, DB, AM, and EV helped EA in drafting and preparing the manuscript. All authors read, revised, and approved the final manuscript.

\section{Competing interests}

The authors declare that they have no competing interests.

Consent for publication

Not applicable.

\section{Ethics approval and consent to participate}

The tissue was obtained and used in accordance with the Declaration of Helsinki and the AMC Research Code and approved by the committee of the UMCU Biobank. This study was also approved by the Ethical Committee of the Medical University of Vienna. All materials have been collected from donors from whom a written informed consent for the use of the material for research purposes had been obtained by the Bloemenhove Clinic (Heemstede, The Netherlands); these informed consents are kept together with the medical record of the donor by the clinic.

\section{Author details}

${ }^{1}$ Academic Medical Center, Department of (Neuro)Pathology, University of Amsterdam, Meibergdreef 9, 1105 AZ Amsterdam, The Netherlands. ${ }^{2}$ Department of Pediatrics, Medical University Vienna, Vienna, Austria. ${ }^{3}$ Department of Neurosurgery, Medical University Vienna, Vienna, Austria. ${ }^{4}$ Department of Pathology, Medical University Vienna, Vienna, Austria. ${ }^{5}$ Department of Pathology, Rudolf Magnus Institute for Neuroscience, University Medical Center Utrecht, Utrecht, The Netherlands. ${ }^{6}$ Department of Neurosurgery, Rudolf Magnus Institute for Neuroscience, University Medical Center Utrecht, Utrecht, The Netherlands. ${ }^{7}$ Swammerdam Institute for Life Sciences, Center for Neuroscience, University of Amsterdam, Amsterdam, The Netherlands. ${ }^{8}$ Stichting Epilepsie Instellingen Nederland (SEIN), Heemstede, The Netherlands.

Received: 5 April 2016 Accepted: 18 July 2016 Published online: 26 August 2016 


\section{References}

1. Djaballah H, Rowe AJ, Harding SE, Rivett AJ. The multicatalytic proteinase complex (proteasome): structure and conformational changes associated with changes in proteolytic activity. Biochem J. 1993;292(Pt 3):857-62.

2. Coux O, Tanaka K, Goldberg AL. Structure and functions of the $20 \mathrm{~S}$ and $26 \mathrm{~S}$ proteasomes. Annu Rev Biochem. 1996;65:801-47.

3. Orlowski M, Wilk S. Catalytic activities of the $20 \mathrm{~S}$ proteasome, a multicatalytic proteinase complex. Arch Biochem Biophys. 2000:383:1-16.

4. Jung $T$, Grune $T$. The proteasome and the degradation of oxidized proteins: part l_structure of proteasomes. Redox Biol. 2013;1:178-82.

5. Groll M, Ditzel L, Lowe J, Stock D, Bochtler M, Bartunik HD, Huber R. Structure of 20S proteasome from yeast at 2.4 A resolution. Nature. 1997;386:463-71.

6. Tai HC, Besche H, Goldberg AL, Schuman EM: Characterization of the brain 265 proteasome and its interacting proteins. Front Mol Neurosci 2010, 3

7. Aki M, Shimbara N, Takashina M, Akiyama K, Kagawa S, Tamura T, Tanahashi N, Yoshimura T, Tanaka K, Ichihara A. Interferon-gamma induces different subunit organizations and functional diversity of proteasomes. J Biochem. 1994;115:257-69.

8. Tanaka K, Kasahara M. The MHC class I ligand-generating system: roles of immunoproteasomes and the interferon-gamma-inducible proteasome activator PA28. Immunol Rev. 1998;163:161-76.

9. Groettrup M, Kirk CJ, Basler M. Proteasomes in immune cells: more than peptide producers? Nat Rev Immunol. 2010;10:73-8.

10. Hensley SE, Zanker D, Dolan BP, David A, Hickman HD, Embry AC, Skon CN, Grebe KM, Griffin TA, Chen W, et al. Unexpected role for the immunoproteasome subunit LMP2 in antiviral humoral and innate immune responses. J Immunol. 2010;184:4115-22

11. Kruger E, Kloetzel PM. Immunoproteasomes at the interface of innate and adaptive immune responses: two faces of one enzyme. Curr Opin Immunol. 2012:24:77-83

12. Diaz-Hernandez M, Hernandez F, Martin-Aparicio E, Gomez-Ramos P, Moran MA, Castano JG, Ferrer I, Avila J, Lucas JJ. Neuronal induction of the immunoproteasome in Huntington's disease. J Neurosci. 2003;23:11653-61.

13. Puttaparthi K, Elliott JL. Non-neuronal induction of immunoproteasome subunits in an ALS model: possible mediation by cytokines. Exp Neurol. 2005:196:441-51.

14. Orre M, Kamphuis W, Dooves S, Kooijman L, Chan ET, Kirk CJ, Dimayuga Smith $\mathrm{V}$, Koot S, Mamber C, Jansen AH, et al. Reactive glia show increased immunoproteasome activity in Alzheimer's disease. Brain. 2013;136:1415-31.

15. Bendotti $C$, Marino M, Cheroni C, Fontana E, Crippa V, Poletti A, De Biasi S. Dysfunction of constitutive and inducible ubiquitin-proteasome system in amyotrophic lateral sclerosis: implication for protein aggregation and immune response. Prog Neurobiol. 2012;97:101-26.

16. Jansen $\mathrm{AH}$, Reits $\mathrm{EA}$, Hol EM. The ubiquitin proteasome system in glia and its role in neurodegenerative diseases. Front Mol Neurosci. 2014;7:73.

17. Mishto M, Ligorio C, Bellavista E, Martucci M, Santoro A, Giulioni M, Marucci G, Franceschi C. Immunoproteasome expression is induced in mesial temporal lobe epilepsy. Biochem Biophys Res Commun. 2011;408:65-70.

18. Mishto M, Raza ML, de Biase D, Ravizza T, Vasuri F, Martucci M, Keller C, Bellavista E, Buchholz TJ, Kloetzel PM, et al. The immunoproteasome beta5i subunit is a key contributor to ictogenesis in a rat model of chronic epilepsy. Brain Behav Immun. 2015;49:188-96.

19. Wong M. Mammalian target of rapamycin (mTOR) activation in focal cortical dysplasia and related focal cortical malformations. Exp Neurol. 2013;244:22-6.

20. Aronica E, Crino PB. Epilepsy related to developmental tumors and malformations of cortical development. Neurotherapeutics. 2014;11:251-68.

21. Blumcke I, Spreafico R. An international consensus classification for focal cortical dysplasias. Lancet Neurol. 2011;10:26-7.

22. Samueli S, Abraham K, Dressler A, Groeppel G, Jonak C, Muehlebner A, Prayer D, Reitner A, Feucht M, Padiatrisches TSCZW. Tuberous sclerosis complex: new criteria for diagnostic work-up and management. Wien Klin Wochenschr. 2015;127:619-30.

23. Vasuri F, Capizzi E, Bellavista E, Mishto M, Santoro A, Fiorentino M, Capri M, Cescon M, Grazi GL, Grigioni WF, et al. Studies on immunoproteasome in human liver. Part I: absence in fetuses, presence in normal subjects, and increased levels in chronic active hepatitis and cirrhosis. Biochem Biophys Res Commun. 2010;397:301-6.

24. Mishto M, Bellavista E, Santoro A, Stolzing A, Ligorio C, Nacmias B, Spazzafumo L, Chiappelli M, Licastro F, Sorbi S, et al. Immunoproteasome and LMP2 polymorphism in aged and Alzheimer's disease brains. Neurobiol Aging. 2006;27:54-66.
25. Prabowo AS, van Scheppingen J, lyer AM, Anink JJ, Spliet WG, van Rijen PC, Schouten-van Meeteren AY, Aronica E. Differential expression and clinical significance of three inflammation-related microRNAs in gangliogliomas. J Neuroinflammation. 2015:12:97.

26. Iyer A, van Scheppingen J, Anink J, Milenkovic I, Kovacs GG, Aronica E. Developmental patterns of DR6 in normal human hippocampus and in Down syndrome. J Neurodev Disord. 2013;5:10.

27. Ravizza T, Boer K, Redeker S, Spliet WG, van Rijen PC, Troost D, Vezzani A, Aronica $\mathrm{E}$. The IL-1beta system in epilepsy-associated malformations of cortical development. Neurobiol Dis. 2006;24:128-43.

28. Aronica E, Gorter JA, Rozemuller AJ, Yankaya B, Troost D. Interleukin-1 beta down-regulates the expression of metabotropic glutamate receptor 5 in cultured human astrocytes. J Neuroimmunol. 2005;160:188-94.

29. Iyer A, Zurolo E, Prabowo A, Fluiter K, Spliet WG, van Rijen PC, Gorter JA, Aronica E. MicroRNA-146a: a key regulator of astrocyte-mediated inflammatory response. PLoS One. 2012;7:e44789.

30. Zurolo E, de Groot M, lyer A, Anink J, van Vliet EA, Heimans JJ, Reijneveld JC, Gorter JA, Aronica E. Regulation of Kir4.1 expression in astrocytes and astrocytic tumors: a role for interleukin-1 beta. J Neuroinflammation. 2012:9:280.

31. Ramakers C, Ruijter JM, Deprez RH, Moorman AF. Assumption-free analysis of quantitative real-time polymerase chain reaction (PCR) data. Neurosci Lett. 2003;339:62-6.

32. Ruijter JM, Ramakers C, Hoogaars WM, Karlen Y, Bakker O, van den Hoff MJ, Moorman AF. Amplification efficiency: linking baseline and bias in the analysis of quantitative PCR data. Nucleic Acids Res. 2009;37:e45.

33. Palmini A, Najm I, Avanzini G, Babb T, Guerrini R, Foldvary-Schaefer N, Jackson G, Luders HO, Prayson R, Spreafico R, Vinters HV. Terminology and classification of the cortical dysplasias. Neurology. 2004;62:S2-8.

34. Boer K, Jansen F, Nellist M, Redeker S, van den Ouweland AM, Spliet WG, van Nieuwenhuizen O, Troost D, Crino PB, Aronica E. Inflammatory processes in cortical tubers and subependymal giant cell tumors of tuberous sclerosis complex. Epilepsy Res. 2008;78:7-21.

35. Iyer A, Zurolo E, Spliet WG, van Rijen PC, Baayen JC, Gorter JA, Aronica E. Evaluation of the innate and adaptive immunity in type I and type II focal cortical dysplasias. Epilepsia. 2010;51:1763-73.

36. Vezzani A, Aronica E, Mazarati A, Pittman QJ. Epilepsy and brain inflammation. Exp Neurol. 2013;244:11-21

37. Wojcik C, DeMartino GN. Intracellular localization of proteasomes. Int J Biochem Cell Biol. 2003;35:579-89.

38. Ding Q, Keller JN. Proteasomes and proteasome inhibition in the central nervous system. Free Radic Biol Med. 2001;31:574-84.

39. Kremer M, Henn A, Kolb C, Basler M, Moebius J, Guillaume B, Leist M, Van den Eynde BJ, Groettrup M. Reduced immunoproteasome formation and accumulation of immunoproteasomal precursors in the brains of lymphocytic choriomeningitis virus-infected mice. J Immunol. 2010;185:5549-60.

40. Wehenkel M, Ban JO, Ho YK, Carmony KC, Hong JT, Kim KB. A selective inhibitor of the immunoproteasome subunit LMP2 induces apoptosis in PC-3 cells and suppresses tumour growth in nude mice. Br J Cancer. 2012;107:53-62.

41. Hegde AN, Upadhya SC. Proteasome and transcription: a destroyer goes into construction. Bioessays. 2006;28:235-9.

42. Kodadek T. No splicing, no dicing: non-proteolytic roles of the ubiquitinproteasome system in transcription. J Biol Chem. 2010;285:2221-6.

43. McCarthy MK, Weinberg JB. The immunoproteasome and viral infection: a complex regulator of inflammation. Front Microbiol. 2015;6:21.

44. van Deventer $\mathrm{S}$, Neefjes J. The immunoproteasome cleans up after inflammation. Cell. 2010;142:517-8.

45. Butler T, Li Y, Tsui W, Friedman D, Maoz A, Wang X, Harvey P, Tanzi E, Morim S, Kang Y, Mosconi L, Talos D, Kuzniecky R, Vallhabjosula S, Thesen T, Glodzik L, Ichise M, Silbersweig D, Stern E, de Leon MJ, French J. Transient and chronic seizure-induced inflammation in human focal epilepsy. Epilepsia. 2016. doi:10.1111/epi.13457

46. Mühlebner A, van Scheppingen J, Hulshof HM, Scholl T, lyer AM, Anink JJ, van den Ouweland AM, Nellist MD, Jansen FE, Spliet WG, Krsek P, Benova B, Zamecnik J, Crino PB, Prayer D, Czech T, Wöhrer A, Rahimi J, Höftberger R, Hainfellner JA, Feucht M, Aronica E. Novel histopathological patterns in cortical tubers of epilepsy surgery patients with tuberous sclerosis complex. PLoS One. 2016;11:e0157396.

47. Boer K, Crino PB, Gorter JA, Nellist M, Jansen FE, Spliet WG, van Rijen PC, Wittink FR, Breit TM, Troost D, et al. Gene expression analysis of tuberous sclerosis complex cortical tubers reveals increased expression of adhesion and inflammatory factors. Brain Pathol. 2010;20:704-19. 
48. Prabowo AS, Anink JJ, Lammens M, Nellist M, van den Ouweland AM, Adle-Biassette H, Sarnat HB, Flores-Sarnat L, Crino PB, Aronica E. Fetal brain lesions in tuberous sclerosis complex: TORC1 activation and inflammation. Brain Pathol. 2013:23:45-59.

49. Ebstein F, Kloetzel PM, Kruger E, Seifert U. Emerging roles of immunoproteasomes beyond MHC class I antigen processing. Cell Mol Life Sci. 2012;69:2543-58

50. Basler M, Kirk CJ, Groettrup M. The immunoproteasome in antigen processing and other immunological functions. Curr Opin Immunol. 2013;25:74-80.

51. Warnatsch A, Bergann T, Kruger E. Oxidation matters: the ubiquitin proteasome system connects innate immune mechanisms with MHC class I antigen presentation. Mol Immunol. 2013;55:106-9.

52. Maldonado M, Kapphahn RJ, Terluk MR, Heuss ND, Yuan C, Gregerson DS, Ferrington DA. Immunoproteasome deficiency modifies the alternative pathway of NFkappaB signaling. PLoS One. 2013;8:e56187.

53. Pintado C, Gavilan MP, Gavilan E, Garcia-Cuervo L, Gutierrez A, Vitorica J, Castano A, Rios RM, Ruano D. Lipopolysaccharide-induced neuroinflammation leads to the accumulation of ubiquitinated proteins and increases susceptibility to neurodegeneration induced by proteasome inhibition in rat hippocampus. J Neuroinflammation. 2012;9:87.

54. Prabowo AS, lyer AM, Anink JJ, Spliet WG, van Rijen PC, Aronica E. Differential expression of major histocompatibility complex class I in developmental glioneuronal lesions. J Neuroinflammation. 2013;10:12.

55. Lim HK, Choi YA, Park W, Lee T, Ryu SH, Kim SY, Kim JR, Kim JH, Baek SH. Phosphatidic acid regulates systemic inflammatory responses by modulating the Akt-mammalian target of rapamycin-p70 S6 kinase 1 pathway. J Biol Chem. 2003;278:45117-27.

56. Schmitz F, Heit A, Dreher S, Eisenacher K, Mages J, Haas T, Krug A, Janssen KP, Kirschning CJ, Wagner H. Mammalian target of rapamycin (mTOR) orchestrates the defense program of innate immune cells. Eur J Immunol. 2008;38:2981-92.

57. Weichhart T, Saemann MD. The multiple facets of mTOR in immunity. Trends Immunol. 2009:30:218-26.

58. Bejarano E, Rodriguez-Navarro JA. Autophagy and amino acid metabolism in the brain: implications for epilepsy. Amino Acids. 2015:47:2113-26.

59. Bockaert J, Marin P. mTOR in brain physiology and pathologies. Physiol Rev. 2015;95:1157-87

60. Yasin SA, Ali AM, Tata M, Picker SR, Anderson GW, Latimer-Bowman E, Nicholson SL, Harkness W, Cross JH, Paine SM, Jacques TS. mTORdependent abnormalities in autophagy characterize human malformations of cortical development: evidence from focal cortical dysplasia and tuberous sclerosis. Acta Neuropathol. 2013;126:207-18.

61. Lilienbaum A. Relationship between the proteasomal system and autophagy. Int J Biochem Mol Biol. 2013;4:1-26.

62. Zhang HM, Fu J, Hamilton R, Diaz V, Zhang Y. The mammalian target of rapamycin modulates the immunoproteasome system in the heart. J Mol Cell Cardiol. 2015;86:158-67.

63. van Vliet EA, Forte G, Holtman L, den Burger JC, Sinjewel A, de Vries HE, Aronica E, Gorter JA. Inhibition of mammalian target of rapamycin reduces epileptogenesis and blood-brain barrier leakage but not microglia activation. Epilepsia. 2012;53:1254-63.

64. Muchamuel T, Basler M, Aujay MA, Suzuki E, Kalim KW, Lauer C, Sylvain C, Ring ER, Shields J, Jiang J, et al. A selective inhibitor of the immunoproteasome subunit LMP7 blocks cytokine production and attenuates progression of experimental arthritis. Nat Med. 2009;15:781-7.

65. Dou QP, Zonder JA. Overview of proteasome inhibitor-based anti-cance therapies: perspective on bortezomib and second generation proteasome inhibitors versus future generation inhibitors of ubiquitin-proteasome system. Curr Cancer Drug Targets. 2014;14:517-36.

66. Miller Z, Ao L, Kim KB, Lee W. Inhibitors of the immunoproteasome: current status and future directions. Curr Pharm Des. 2013;19:4140-51.

67. Miller Z, Lee W, Kim KB. The immunoproteasome as a therapeutic target for hematological malignancies. Curr Cancer Drug Targets. 2014;14:537-48.

68. Basler M, Mundt S, Bitzer A, Schmidt C, Groettrup M. The immunoproteasome: a novel drug target for autoimmune diseases. Clin Exp Rheumatol. 2015; 33:574-79.

69. Bellavista E, Santoro A, Galimberti D, Comi C, Luciani F, Mishto M. Current understanding on the role of standard and immunoproteasomes in inflammatory/immunological pathways of multiple sclerosis. Autoimmune Dis. 2014;2014:739705
70. Ferrington DA, Hussong SA, Roehrich H, Kapphahn RJ, Kavanaugh SM, Heuss ND, Gregerson DS. Immunoproteasome responds to injury in the retina and brain. J Neurochem. 2008;106:158-69.

71. Seifert U, Bialy LP, Ebstein F, Bech-Otschir D, Voigt A, Schroter F, Prozorovski T, Lange N, Steffen J, Rieger M, et al. Immunoproteasomes preserve protein homeostasis upon interferon-induced oxidative stress. Cell. 2010;142:613-24.

72. Malik AR, Liszewska E, Skalecka A, Urbanska M, lyer AM, Swiech LJ, Perycz M, Parobczak K, Pietruszka P, Zarebska MM, et al. Tuberous sclerosis complex neuropathology requires glutamate-cysteine ligase. Acta Neuropathol Commun. 2015;3:48

73. Iyer A, Prabowo A, Anink J, Spliet WG, van Rijen PC, Aronica E: Cell injury and premature neurodegeneration in focal malformations of cortical development. Brain pathology 2013

74. Ding $M$, Shen $K$. The role of the ubiquitin proteasome system in synapse remodeling and neurodegenerative diseases. Bioessays. 2008;30:1075-83.

75. Lazarevic V, Pothula S, Andres-Alonso M, Fejtova A. Molecular mechanisms driving homeostatic plasticity of neurotransmitter release. Front Cell Neurosci. 2013;7:244.

\section{Submit your next manuscript to BioMed Central and we will help you at every step:}

- We accept pre-submission inquiries

- Our selector tool helps you to find the most relevant journal

- We provide round the clock customer support

- Convenient online submission

- Thorough peer review

- Inclusion in PubMed and all major indexing services

- Maximum visibility for your research

Submit your manuscript at www.biomedcentral.com/submit
C Biomed Central 